\title{
Practical multi-area bi-objective environmental economic dispatch equipped with a hybrid gradient search method and improved Jaya algorithm
}

DOI:

10.1049/iet-gtd.2016.0333

\section{Document Version}

Accepted author manuscript

Link to publication record in Manchester Research Explorer

Citation for published version (APA):

Azizipanah-Abarghooee, R., Dehghanian, P., \& Terzija, V. (2016). Practical multi-area bi-objective environmental economic dispatch equipped with a hybrid gradient search method and improved Jaya algorithm. IET Generation, Transmission and Distribution, 10(14), 3580-3596. https://doi.org/10.1049/iet-gtd.2016.0333

Published in:

IET Generation, Transmission and Distribution

\section{Citing this paper}

Please note that where the full-text provided on Manchester Research Explorer is the Author Accepted Manuscript or Proof version this may differ from the final Published version. If citing, it is advised that you check and use the publisher's definitive version.

\section{General rights}

Copyright and moral rights for the publications made accessible in the Research Explorer are retained by the authors and/or other copyright owners and it is a condition of accessing publications that users recognise and abide by the legal requirements associated with these rights.

\section{Takedown policy}

If you believe that this document breaches copyright please refer to the University of Manchester's Takedown Procedures [http://man.ac.uk/04Y6Bo] or contact uml.scholarlycommunications@manchester.ac.uk providing relevant details, so we can investigate your claim.

\section{OPEN ACCESS}




\title{
A Practical Multi-Area Bi-Objective Environmental Economic Dispatch Equipped with A Hybrid Gradient Search Method and Improved Jaya Algorithm
}

\author{
Rasoul Azizipanah-Abarghooee ${ }^{\mathrm{a}^{*}}$, Payman Dehghanian $^{\mathrm{b}}$, and Vladimir Terzija ${ }^{\mathrm{a}}$ \\ ${ }^{\text {a }}$ Department of Electrical and Electronic Engineering, The University of Manchester, Manchester, M13 9PL, UK \\ b Department of Electrical and Computer Engineering, Texas A\&M University, College Station, TX, 77843, USA.
}

\begin{abstract}
:
Generation dispatch decision making integrated into a centralized wholesale electricity market has been always a challenging concern for transmission system operators and has progressively received significant attention in recent years. The reason lies mainly in the complex and highly-interconnected structure of the grid, escalated demand, and the crisis of the amount and price of energy. For the dispatch solutions to be highly reliable with an acceptable level of accuracy, several factors of notable importance need to be well taken into account, among which one can mention the valve-point effect, multiple fuel options and disjoint prohibited zones, up/down ramp rate requirements of generating units, as well as the spinning reserve constraints which, in turn, intensify the non-smoothness, nonconvexity, non-linearity, and dynamic restriction of such combinatorial hard problems. This paper proposes a new optimization toolset for the bi-objective multi-area economic dispatch problem to determine the transmission interface power flow and power output of generating units while satisfying system demand and security constraints at each area. The proposed architecture builds upon an improved gradient-based Jaya algorithm to generate a feasible set of Pareto optimal solutions corresponding to the operation cost and fuel combustion emission calculated through a new robust bi-objective gradient based method. The projected algorithm is proved to be capable of finding the robust global or near-global Pareto solutions fast and accurate.
\end{abstract}

Keywords: Bi-objective gradient-based technique; economic dispatch; environmental; heuristic; improved Jaya algorithm, optimization.

E-mail: rasoul.azizipanah-abarghooee@postgrad.manchester.ac.uk, payman.dehghanian@ieee.org; Vladimir.terzija@manchester.ac.uk.

*Corresponding author address: Department of Electrical and Electronic Engineering, The University of Manchester, Manchester, M13 9PL, UK. 


\section{Nomenclature}

\section{A. Indices}

ger

$i, j$

iter

$k, k^{\prime}$

$n$

$n f_{i}$

obj, $t$

$\kappa$

\section{B. Constants}

Iteration index of the gradient method (GM).

Generating unit indices.

Iteration index of the proposed algorithm.

Area index.

Particle index.

Fuel type index for generating unit $i$.

Objective function and time step indices, respectively.

Disjoint prohibited zone (DPZ) index.

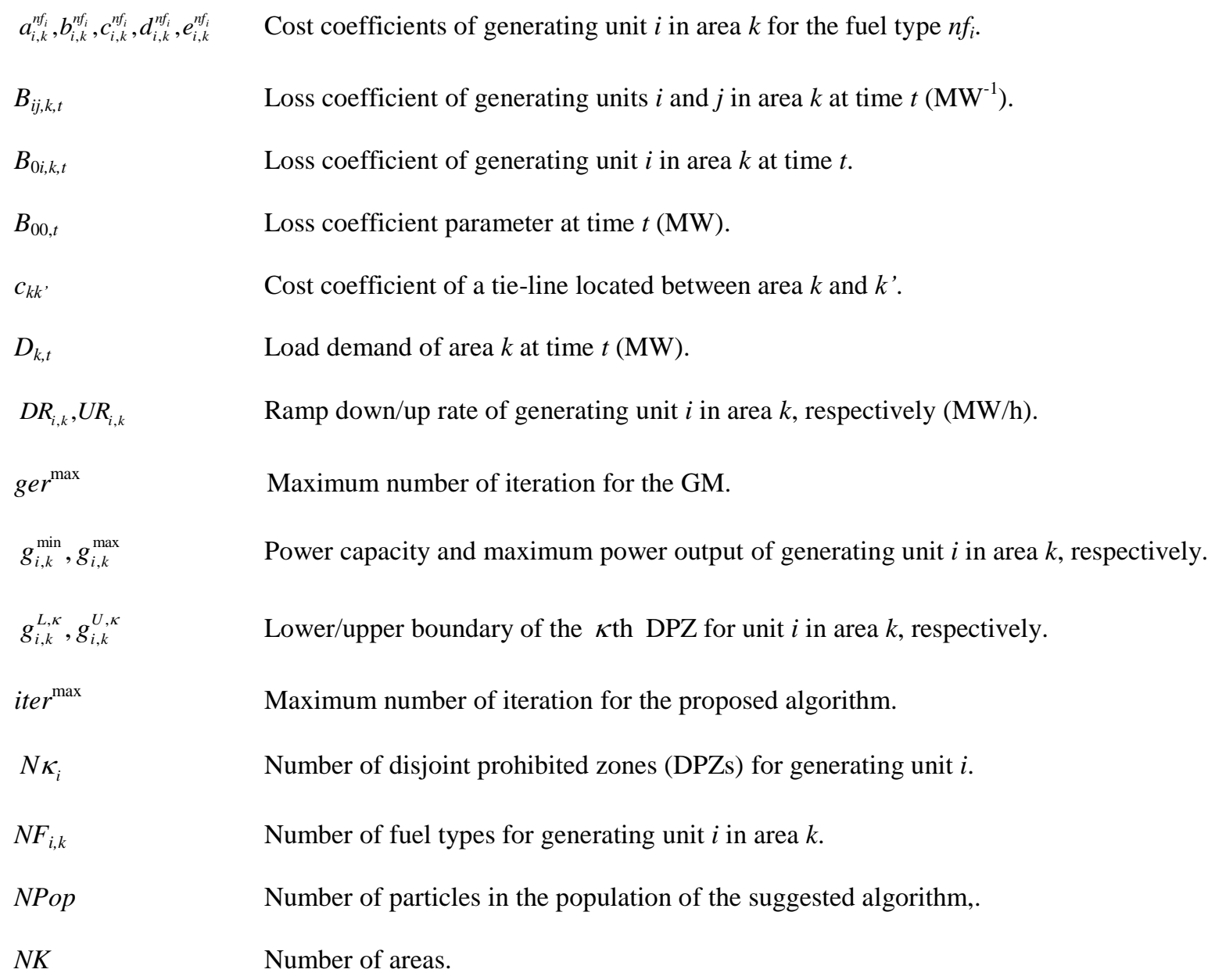


NUK Number of generating units in area $k$.

Rand $1_{m, n}^{\text {iter }}$, Rand $2_{m, n}^{\text {iter }} \quad$ Random function generators in the range $[0,1]$ for $m^{\text {th }}$ member of the agent $n$ at iteration iter.

$r_{k, t}^{u p}, r_{k, t}^{d n} \quad$ Required up/down spinning reserve for area $k$ at time $t$, respectively (MW).

$T i e_{k k^{\prime}, t}^{\min }, T i e_{k k^{\prime}, t}^{\max } \quad$ Minimum/maximum power flow limits of tie-lie $k k^{\prime}$ at time $t$, respectively.

$\alpha_{i, k}, \beta_{i, k}, \gamma_{i, k}, \zeta_{i, k}, \lambda_{i, k} \quad$ Emission coefficients of generating unit $i$ in area $k$.

$\alpha^{\text {ger }}, m^{\text {ger }} \quad$ Constant parameters in the iteration ger of the GM.

\section{Variables}

\begin{tabular}{|c|c|}
\hline$F_{1}(\mathbf{X})$ & Function of the total operation cost. \\
\hline$F_{2}(\mathbf{X})$ & Function of the total emission. \\
\hline$F_{e}\left(g_{i, k, t}\right)$ & Emission function of generating unit $i$ in area $k$ at time $t(\$)$. \\
\hline$F_{g}\left(g_{i, k, t}\right)$ & Fuel cost function of generating unit $i$ in area $k$ at time $t(\$)$. \\
\hline$F_{T i e}\left(T i e_{k k, t}\right)$ & Transmission cost function of a tie-line connecting between area $k$ and $k^{\prime}$ at time $t(\$)$. \\
\hline G & Vector of system generating units. \\
\hline $\mathbf{G}_{k, t}$ & Interchange power vector between area $k$ and others at time $t$. \\
\hline$g_{i, k, t}$ & Power output of generating unit $i$ in area $k$ at time $t(\mathrm{MW})$. \\
\hline $\bar{g}_{i, k, t}, \underline{g}_{i, k, t}$ & Upper/lower limit of $i^{\text {th }}$ generating unit output power in area $k$ at time $t$, respectively (MW). \\
\hline$g_{k, t}^{v i o}$ & Power mismatch of area $k$ at time $t(\mathrm{MW})$. \\
\hline $\operatorname{Loss}_{k, t}$ & Total real power losses of area $k$ at time $t(\mathrm{MW})$. \\
\hline$r_{i, k, t}^{u p}, r_{i, k, t}^{d n}$ & Up/down spinning reserve of the generating unit $i$ in area $k$ at time $t$, respectively (MW). \\
\hline$R_{k, t}^{u p}, R_{k, t}^{d n}$ & Total up/down spinning reserve of all generating units in area $k$ at time $t$, respectively (MW). \\
\hline Tie & Tie-line power flow vector. \\
\hline $\mathbf{T i e}_{k, t}$ & Power flow vector for all tie-lines connecting to area $k$ at time $t$. \\
\hline $\mathrm{Tie}_{k k^{\prime}, t}$ & Power flow from area $k$ to $k^{\prime}$ at time $t$. \\
\hline $\mathbf{X}$ & Vector of decision variables. \\
\hline
\end{tabular}




$\mathbf{X}^{\text {worst }, \text { iter }}$
The worst solution among all particles in iteration iter of the proposed algorithm.
$\mathbf{X}^{\text {best }, \text { iter }}$
The $m^{\text {th }}$ member of particle $n$ at iteration iter of the proposed algorithm.
$x_{m, n}^{\text {iter }}$
$x_{m}^{\text {best }, \text { iter }}, x_{m}^{\text {worst }, \text { iter }}$
The $m^{\text {th }}$ member of the best and worst solutions found at iteration iter of the proposed
algorithm, respectively.
$\lambda^{\text {ger }}$

\section{Introduction}

Deregulation in nowadays electric power system operation, monitoring and control offers a power pool environment enabling different utility operators to participate in energy and reserve interchange from the areas with cheaper generations to those expensive ones through tie-lines. In this way, achieving the least operation cost and fuel combustion emission with optimum reliability and security performance compared to the isolated operation modes would be possible. Whilst the majority of existing research works focus on either the mono-area mono-objective economic dispatch (ED), or mono-area bi-objective ED (BED), or multi-area mono-objective ED (MED) formulations, this study deals with the multi-area bi-objective ED (MBED) through which fast and robust power generation schedules of different thermal generating units (TUs) as well as the tie-lines power flows would be potentially optimized while simultaneously lowering the operation cost and emissions subject to several operational and physical network constraints. In the classical ED formulation, the TUs' cost functions are assumed to be quadratic polynomials which are convex, differentiable, and smoothly augmenting functions. As a matter of fact, the valve point effect, multiple fuel options, disjoint prohibited zones (DPZs), up/down ramp rate limits, and the system security requirements are also other critical concerns bringing about additional complexities to optimal operation of the multi-area electric power systems. In the power pool electricity market environment, the economic, environmental, and technical characteristics of the grid as well as the reliability performance of power generation system can be further improved if spinning reserve restrictions in all the interdependent areas are well formulated. Consequently, providing the non-dominated Pareto optimal solutions is challenging when it comes to the MBED problems.

In general, the solution methodologies proposed in the existing literature for solving the ED formulations can be categorized into two major groups: mathematical programming techniques and meta-heuristic optimization methods. 


\section{IET GENERATION, TRANSMISSION \& DISTRIBUTION}

In view of the former category, several approaches are available to solve the ED problems, among which one can mention the linear programming (LP) method [1], analytical techniques [2], and direct Newton-Raphson method [3] are also suggested to solve the BED formulations. A linear optimization process [4] and adaptive Lagrange relaxation approach [5] are suggested to solve the MED problems. While some of such mathematical algorithms are currently employed by some transmission system operators (TSOs) due to their higher convergence speed and unique solution sets offered, they majorly suffer from some notable bottlenecks as follows: (a) employing the derivative operations (b) Sacrificing the desirable accuracy using linearization; (c) Incapable in handling difficult inequality constraints; (d) Entrapping in local optimal positions; (e) High execution run-time in large scale electric power systems; and (f) Inability to effectively handle the complex bi-objective optimization problems (BOPs). To tackle one or two aforementioned issues, the method of reformulating the relaxation has attracted significant interests in recent years. A mixed-integer quadratic programming (MIQP) combined with the big M technique were suggested in [6] for the search of global optimal solution and complexity moderation. However, this model is unable to consider the transmission network losses constraints. A self-organizing computation architecture on the basis of distributed economic dispatch is presented in [7], [8] to handle the control and monitoring concerns of a smart micro-grid with minimum centralized data acquisition requirements. A decentralized and self-organizing approach to solve the ED problems is developed in [9]. Such frameworks are flexible, stable and scalable, and can be implemented for handling the ED problems with convex and smooth objective functions. Further attempts are made in [9] to incorporate the transmission line losses into the problem formulation through local agents governed by a central authority. Incorporation of transmission losses into a non-convex ED problem using a fully decentralized architecture is introduced in [10]. Albeit a compact formulation was presented in [11] to provide a continuous feasible region for the TUs with the restriction of DPZs, they would eventually find a local optimal solution. A formulation of vanishing restrictions on the basis of semi-definite programming (SDP) relaxation was also suggested in [12] which could not guarantee the global or near-global solution if the relaxation framework has a gap to the original one.

In response to all the mentioned concerns, many meta-heuristic techniques have been proposed in the literature. The Bacterial Foraging (BF) [13] is among such suggestions to solve the MED problem. In addition, multi-objective Particle Swarm Optimization (MOPSO) [13], strength Pareto evolutionary algorithm [14] and Non-Dominated Sorting Genetic Algorithm (NSGA) [15] are proposed to apply to the BED optimization problems. The dynamically 


\section{IET GENERATION, TRANSMISSION \& DISTRIBUTION}

controlled PSO (DCPSO) [16], Harmony Search (HS) [17], an improved PSO [18], Teaching-Learning-Based Optimization (TLBO) [19], Artificial Bee Colony Optimization (ABCO) [20], and PSO [21] are developed to handle the MED problems. An Improved Differential Evolution (IDE) [22], Chaotic Global Best Artificial Bee Colony (CGBABC) [23] and PSO [24] are also developed to handle the MBED challenges. Due to the strong capability of the meta-heuristic techniques in dealing with the mentioned problems and their straight-forward implementation, they are widely employed to handle complex problems in electric power system domain [25]. However, there exists several disadvantages of such algorithms as follows: (a) slow and premature convergence; (b) sensitivity to the settings and parameters; and (c) trapping in the local optima.

The key innovation of this study is to hybridize the mathematical gradient based method (GM) and improved Jaya algorithm (IJA) as a meta-heuristic approach to exploit their complementary and advantageous characteristics in finding the robust and optimal non-dominated solutions in Pareto frontier very fast. The essential concept of the new Jaya algorithm (JA) is designed in such a way that the existing solutions in the search space should constantly move towards the best agent and avoid the worst one [26]. The main feature of the proposed algorithm, which makes it unique in comparison with other similar meta-heuristic algorithms, is that it does not require tuning of any algorithmic parameter. Although the superiority of the JA algorithm over the 54 benchmark functions has been investigated in [26], it may steadily stop generating the successful solutions though the population when it comes to highly complex non-linear problems in electric power systems. Therefore, a new mutation strategy is added to the original structure to strongly improve the exploration and exploitation process of JA. On the other hand, the rapid convergence of the GM, by appropriately exploiting the gradient information and providing a robust solution compared to the IJA - that does not calculate gradient - offers motivations to combine it with the IJA. With such additions and modifications, the projected improved gradient based Jaya algorithm (IGJA) would provide attractive benefits in terms of considerably-fast convergence, efficient robustness, well-distributed and uniform Pareto optimal frontier, and scalable features for real-world implementations. To prune the repository containing the non-dominated solutions and select the best compromised solution, a fuzzy clustering method is employed as the final decision making mechanism. Case study results well verify the acceptable performance of the suggested algorithm and its interesting promises for real-world implementations. 
IET GENERATION, TRANSMISSION \& DISTRIBUTION

\section{Problem Formulation}

The decision variables, objective functions and constraints of the proposed MBED are as follows:

$\mathbf{X}=\left[\begin{array}{ll}\mathbf{G} & \mathbf{T i e}\end{array}\right]$

$\mathbf{G}=\left[\begin{array}{lllll}\mathbf{G}_{1, t} & \cdots & \mathbf{G}_{k, t} & \cdots & \mathbf{G}_{N K, t}\end{array}\right]$

$\mathbf{G}_{k, t}=\left[\begin{array}{lllll}g_{1, k, t} & \cdots & g_{i, k, t} & \cdots & g_{N U K, k, t}\end{array}\right]$

$\mathbf{T i e}=\left[\begin{array}{lllll}\mathbf{T i e}_{1, t} & \cdots & \mathbf{T i e}_{k, t} & \cdots & \mathbf{T i e}_{N K-1, t}\end{array}\right]$

$\mathbf{T i e}_{k, t}=\left[\begin{array}{lllll}T i e_{k k+1, t} & \cdots & \text { Ti }_{k k^{\prime}, t} & \cdots & \text { Ti } e_{k N K, t}\end{array}\right]$

- Minimize operation cost [4], [19], [24]

$F_{1}(\mathbf{X})=\sum_{k=1}^{N K} \sum_{i=1}^{N U K} F_{g}\left(g_{i, k, t}\right)+\sum_{k=1}^{N K-1} \sum_{k^{\prime}=k+1}^{N K} F_{T i e}\left(T i e_{k k^{\prime}, t}\right)$

- Minimize emissions [22]:

$F_{2}(\mathbf{X})=\sum_{k=1}^{N K} \sum_{i=1}^{N U K} F_{e}\left(g_{i, k, t}\right)$

Subject to:

$F_{g}\left(g_{i, k, t}\right)=\left\{\begin{array}{l}\text { if } g_{i, k}^{\min } \leq g_{i, k, t} \leq g_{i, k}^{1} ; \quad \text { Fuel type } 1 \\ a_{i, k}^{1}+b_{i, k}^{1} g_{i, k, t}+c_{i, k}^{1}\left(g_{i, k, t}\right)^{2}+\left|d_{i, k}^{1} \sin \left(e_{i, k}^{1}\left(g_{i, k}^{\min }-g_{i, k, t}\right)\right)\right| \\ \text { if } g_{i, k}^{1} \leq g_{i, k, t} \leq g_{i, k}^{2} ; \quad \text { Fuel type } 2 \\ a_{i, k}^{2}+b_{i, k}^{2} g_{i, k, t}+c_{i, k}^{2}\left(g_{i, k, t}\right)^{2}+\left|d_{i, k}^{2} \sin \left(e_{i, k}^{2}\left(g_{i, k}^{\min }-g_{i, k, t}\right)\right)\right| \\ \vdots \\ \text { if } g_{i, k}^{N F_{i, k}-1} \leq g_{i, k, t} \leq g_{i, k}^{\max } ; \quad \text { Fuel type } N F_{i, k} \\ a_{i, k}^{N F_{i, k}}+b_{i, k}^{N F_{i, k}} g_{i, k, t}+c_{i, k}^{N F_{i, k}}\left(g_{i, k, t}\right)^{2}+\left|d_{i, k}^{N F_{i, k}} \sin \left(e_{i, k}^{N F_{i, k}}\left(g_{i, k}^{\min }-g_{i, k, t}\right)\right)\right|\end{array}\right.$

$F_{T i e}\left(T i e_{k k^{\prime}, t}\right)=c_{k k^{\prime}} T i e_{k k^{\prime}, t}$

$F_{e}\left(g_{i, k, t}\right)=\alpha_{i, k}+\beta_{i, k} g_{i, k, t}+\gamma_{i, k}\left(g_{i, k, t}\right)^{2}+\zeta_{i, k} \exp \left(\lambda_{i, k} g_{i, k, t}\right)$ 
IET GENERATION, TRANSMISSION \& DISTRIBUTION

$$
\begin{aligned}
& \sum_{i=1}^{N U K} g_{i, k, t}=D_{k, t}+\operatorname{Loss}_{k, t}+\sum_{k^{\prime}=1, k^{\prime} \neq k}^{N K} \operatorname{Ti}_{k k^{\prime}, t} \\
& \operatorname{Loss}_{k, t}=\sum_{i=1}^{N U K} \sum_{j=1}^{N U K} g_{i, k, t} B_{i j, k, t} g_{j, k, t}+\sum_{i=1}^{N U K} B_{0 i, k, t} g_{i, k, t}+B_{00, t} \\
& g_{i, k, t}-g_{i, k, t-1} \leq U R_{i, k} i=1, \ldots, N U K, k=1, \ldots, N K \\
& g_{i, k, t-1}-g_{i, k, t} \leq D R_{i, k} i=1, \ldots, N U K, k=1, \ldots, N K \\
& \underline{g}_{i, k, t} \leq g_{i, k, t} \leq \bar{g}_{i, k, t} i=1, \ldots, N U K, k=1, \ldots, N K \\
& \bar{g}_{i, k, t}=\min \left(g_{i, k}^{\max }, g_{i, k, t-1}+U R_{i, k}\right) i=1, \ldots, N U K, k=1, \ldots, N K \\
& \underline{g}_{i, k, t}=\max \left(g_{i, k}^{\min }, g_{i, k, t-1}-D R_{i, k}\right) i=1, \ldots, N U K, k=1, \ldots, N K
\end{aligned}
$$

$g_{i, k, t} \in\left\{\begin{array}{c}g_{i, k}^{\min } \leq g_{i, k, t} \leq g_{i, k}^{L, 1} \\ \vdots \\ g_{i, k}^{U, \kappa-1} \leq g_{i, k, t} \leq g_{i, k}^{L, \kappa} \quad \kappa=2,3, \ldots, N \kappa_{i}, i=1, \ldots, N U K, k=1, \ldots, N K \\ \vdots \\ g_{i, k}^{U, N \kappa_{i}} \leq g_{i, k, t} \leq g_{i, k}^{\max }\end{array}\right.$

$$
\begin{gathered}
\left(R_{k, t}^{u p}=\sum_{i=1}^{N U K} r_{i, k, t}^{u p}\right) \geq r_{k, t}^{u p} \\
\left(R_{k, t}^{d n}=\sum_{i=1}^{N U K} r_{i, k, t}^{d n}\right) \geq r_{k, t}^{d n}
\end{gathered}
$$$$
r_{i, k, t}^{u p}= \begin{cases}g_{i, k}^{L, \kappa}-g_{i, k, t} & \text { if } g_{i, k}^{L, \kappa}<\left(g_{i, k, t}+\min \left(g_{i, k}^{\max }-g_{i, k, t}, \frac{U R_{i, k}}{6}\right)\right)<g_{i, k}^{U, \kappa} \\ \min \left(g_{i, k}^{\max }-g_{i, k, t}, \frac{U R_{i, k}}{6}\right) & \text { else } \quad \kappa=1, \ldots, N \kappa_{i}, i=1, \ldots, N U K, k=1 \ldots, N K\end{cases}
$$$$
r_{i, k, t}^{d n}= \begin{cases}g_{i, k, t}-g_{i, k}^{U, \kappa-1} & \text { if } g_{i, k}^{L, \kappa-1}<\left(g_{i, k, t}-\min \left(g_{i, k, t}-g_{i, k}^{\min }, \frac{D R_{i, k}}{6}\right)\right)<g_{i, k}^{U, \kappa-1} \\ \min \left(g_{i, k, t}-g_{i, k}^{\min }, \frac{D R_{i, k}}{6}\right) & \text { else } \quad \kappa=1, \ldots, N \kappa_{i}, i=1, \ldots, N U K, k=1 \ldots, N K\end{cases}
$$

$$
T i e_{k k^{\prime}, t}^{\min } \leq T i e_{k k^{\prime}, t} \leq T i e_{k k^{\prime}, t}^{\max } k, k^{\prime}=1, \ldots, N K, k \neq k^{\prime}
$$




\section{IET GENERATION, TRANSMISSION \& DISTRIBUTION}

While the fuel cost of the TUs is traditionally modeled as a quadratic function, there exists, in real world scenarios, several operation intervals and sinusoidal ripples in the cost function of modern TUs mainly due to existence of different fuel types and the steam admission through the valves (valve-point effect), respectively. As a result, the cost function of each TU is defined in constraint (4) considering various fuel types. Such considerations of valvepoint effect brings about additional difficulties as the non-linear feature of the problem search space as well as the number of local optima would escalate. The sinusoidal and quadratic cost functions are compared in Fig. 1(a) and Fig. 1(b) in terms of two-unit cost function surface. Constraint (5) represents the transmission cost for the active power flow through the corresponding tie-line. The released emission of each TU is represented in (6) through a quadratic function plus an exponential term. For the sake of clarity, the exponential and quadratic types of emission functions are portrayed in Fig. 1(c) and Fig. 1(d), respectively. The power balance restriction of each area is referred to in (7). The transmission loss at each area is expressed in (8) using the Kron's loss formula [27]. This quadratic formulation converts the power network operating information with regard to the convoluted currents and voltages into data with reference to the real generation units' power and transmission line's losses employing the B-loss coefficients [27], [28]. As can be seen in (8), the losses are dependent on loading of each individual generating unit through a set of constants. Compared to other loss formula [29], this technique is extensively common in many literature [10], [14], [19], [20], [22], [23] and is derived by Kron [27] using tensorial methods, with a significantly lower computational and measurement requirements [29], [30]. The existence of off-nominal turn ratios and their illustration on an AC power network analyzer with several interconnected transmission systems are considered in tensorial techniques to drive (8). Moreover, Kron's formula is definitely appropriate for transmission networks as the practical computation of B-loss coefficients is based on the fact that the $\mathrm{X} / \mathrm{R}$ (reactance/resistance) ratio is large [31], [32]. Constraints (9) and (10) impose the up and down ramp restrictions, respectively. Owing to the economical, physical, and practical constraints, the certain amounts of minimum and maximum output generations are represented in (11) and (12) for each TU. Due to some physical restrictions, the undivided feasible zone of some TUs is separated into several disjoint sub-feasible zones so that only one is active during each time interval and the TU could continuously change its operation set point within the selected sub-feasible zone. Constraint (13) represents the mentioned sub-feasible zones for each unit. For instance, the feasible solution plane of three TUs with two DPZs is highlighted with oblique black lines in Fig. 2(a). The demand of the system is $D_{k, t}$ and the upper and lower bounds of sub-feasible zones are determined with red, blue and green lines for the respective first, second, and 


\section{IET GENERATION, TRANSMISSION \& DISTRIBUTION}

third TUs. As illustrated, the non-convexity and complicatedness of the problem are intensified considering the DPZs. The system up and down spinning reserve constraints are enforced in (14) and (15), respectively. Up and down spinning reserves are the indispensable requirements of each area to deal with unexpected fluctuations. However, the DPZs strictly pose the restrictions for TUs to participate in load regulations. In contrast to the traditional approach that the TUs with no DPZs were managed to corporate in up and down spinning reserve requirements [33], [34], constraints (16) and (17) illustrate that all the TUs are able to provide the 10-min up/down reserves for which the up and down ramping rates are rationally modeled as $U R_{i, k} / 6$ and $D R_{i, k} / 6$, respectively. As shown, the 10-min up and down reserve capabilities of each TU shrink to its sub-feasible region to avoid the load regulation from DPZs. The spinning reserve satisfaction with and without considering the DPZs for a typical TU is demonstrated in Fig. 2(b). The tie-line power flow limit is eventually reflected in (18).

\section{Figures1 and 2}

\section{Improved Gradient based Jaya Algorithm (IGJA)}

\subsection{Overview of the Original Jaya Algorithm (JA)}

The JA is a novel population-based optimization algorithm which is proposed in [26]. In this paper, the JA comprises a number of different individuals $\left(\mathbf{X}_{n} n=1, \ldots\right.$, NPop ) with unalike fitness function values of $F\left(\mathbf{X}_{n}\right) n=1, \ldots$, NPop . The agents implement the position information of two solutions i.e. the best and the worst ones and update themselves as follows:

$x_{m, n}^{\text {new iter }}=x_{m, n}^{\text {iter }}+\operatorname{rand} 1_{m, n}^{\text {iter }}\left(x_{m}^{\text {best }, \text { iter }}-\left|x_{m, n}^{\text {iter }}\right|\right)-\operatorname{rand} 2_{m . n}^{\text {iter }}\left(x_{m}^{\text {worst iter }}-\left|x_{m, n}^{\text {iter }}\right|\right) ; \forall m, n$, iter

The fitness function of each agent $n$ at iteration iter $\left(F\left(\mathbf{X}_{n}^{\text {iter }}\right)\right)$ is determined as follows:

$$
F\left(\mathbf{X}_{n}^{i t e r}\right)=\omega_{1} \mu_{1}\left(\mathbf{X}_{n}^{i t e r}\right)+\omega_{2} \mu_{2}\left(\mathbf{X}_{n}^{i t e r}\right)
$$

To select the best solution during the JA implementation, the TSO assigns a weighting factor $\left(\omega_{o b j}\right)$ to each objective function that is a given number in the range of $[0,1]$. Moreover, each objective function is mapped into a pseudo-objective value using a fuzzy membership function $\left(\mu_{o b j}\left(\mathbf{X}_{n}^{\text {iter }}\right)\right)$ as follows [15]: 
$\mu_{o b j}\left(\mathbf{X}_{n}^{i t e r}\right)=\left\{\begin{array}{cc}1 & \text { for } F_{o b j}\left(\mathbf{X}_{n}^{i t e r}\right) \leq F_{o b j}^{\min } \\ 0 & \text { for } F_{o b j}\left(\mathbf{X}_{n}^{i t e r}\right) \geq F_{o b j}^{\max } \\ \Delta_{o b j} & \text { else }\end{array}\right.$

where,

$\Delta_{o b j}=\frac{F_{o b j}^{\max }-F_{o b j}\left(\mathbf{X}_{n}^{\text {iter }}\right)}{F_{o b j}^{\max }-F_{o b j}^{\min }}$

In (21) and (22), $o b j \in\{1,2\}, F_{o b j}^{\min }$ and $F_{o b j}^{\max }$ are the minimum and maximum acceptable values of $o b j^{\text {th }}$ objective function, respectively. In each step of the evolutionary algorithms, each candidate solution should be substituted with the new generated individual, obtained through the optimization procedure, if and only if the new one has a better fitness function value. In the JA approach, the new and old solutions are compared to each other according to (20). In this regard, the pseudo-objective value of each candidate solution is determined to normalize the objective function and map them from two discrepant spaces to the same range of $[0,1]$. The TSO is then asked to determine his/her preferred pseudo-objective values, that illustrate the significance of objective function, called weighting factor $\left(\omega_{o b j}\right)$. In this study, the equivalent value of 0.5 are chosen for both $\omega_{1}$ and $\omega_{2}$. Then, equation (20) is deployed to select the better candidate solution which is anticipated to be the closest one with reference to the TSO's preference. The selected candidate solution is participated in the next step of the optimization algorithm (see Fig. 4).

\subsection{Improved JA (IJA)}

In order to enhance the accuracy of the Pareto optimal solutions and restrain the algorithm from a premature convergence, a new mutation strategy is added to the original JA. To implement the proposed strategy, the following procedure should be followed:

Initialize the population and name it as $\mathbf{P}^{1}$.

Set $q_{1}^{1}=\cdots=q_{n}^{1}=\cdots=q_{N P o p}^{1}=0 ; \mathbf{A}=\mathbf{P}^{1}$.

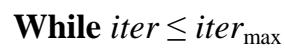

Update the position of each particle using the JA as described in (19).

For $n=1$ to NPop

Select $r_{1} \neq r_{2} \neq r_{3} \neq r_{4}$ from the set $I=\{1,2, . ., N P o p\}$, randomly. 
If $q_{n}^{0}<N P o p / 2$

Let $\mathbf{X}_{r_{1}}^{\text {iter }}, \mathbf{X}_{r_{2}}^{\text {iter }}, \mathbf{X}_{r_{3}}^{\text {iter }}, \mathbf{X}_{r_{4}}^{\text {iter }}$ and $\mathbf{X}_{n}^{\text {iter }}$ be the $r_{1}^{\text {th }}, r_{2}^{\text {th }}, r_{3}^{\text {th }}, r_{4}^{\text {th }}$ and $n^{\text {th }}$ vectors of $\mathbf{P}^{k}$, respectively.

Else

Let $\mathbf{X}_{r_{1}}^{\text {iter }}, \mathbf{X}_{r_{2}}^{\text {iter }}, \mathbf{X}_{r_{3}}^{\text {iter }}, \mathbf{X}_{r_{4}}^{\text {iter }}$ and $\mathbf{X}_{n}^{\text {iter }}$ be the $r_{1}^{\text {th }}, r_{2}^{\text {th }}, r_{3}^{\text {th }}, r_{4}^{\text {th }}$ and $n^{\text {th }}$ vectors of $\mathbf{A}$, respectively.

\section{End If}

Generate a donor vector $\mathbf{V}_{n}^{\text {iter }}=\operatorname{mutate}\left(\mathbf{X}_{r_{1}}^{\text {iter }}, \mathbf{X}_{r_{2}}^{\text {iter }}, \mathbf{X}_{r_{3}}^{\text {iter }}, \mathbf{X}_{r_{4}}^{\text {iter }}\right)$ using (23).

Generate a trial vector $\mathbf{U}_{n}^{\text {iter }}=\operatorname{xover}\left(\mathbf{X}_{n}^{\text {iter }}, \mathbf{V}_{n}^{\text {iter }}\right)$ using (24).

If $F\left(\mathbf{U}_{n}^{\text {iter }}\right)$ is less than $F\left(\mathbf{X}_{n}^{\text {iter }}\right)$

$$
\begin{aligned}
& \mathbf{X}_{n}^{i t e r+1}=\mathbf{U}_{n}^{i t e r} ; \\
& q_{n}^{i t e r+1}=0 ;
\end{aligned}
$$

Update vector A with $\mathbf{U}_{n}^{\text {iter }}$.

\section{Else}

$$
\begin{aligned}
\mathbf{X}_{n}^{\text {iter }+1} & =\mathbf{X}_{n}^{\text {iter }} ; \\
q_{n}^{i t e r+1} & =q_{n}^{\text {iter }}+1 ;
\end{aligned}
$$

\section{End If}

End For (it refers to index $n$ )

End While (it refers to index iter)

The mutate and xover are the mutation operators which are formulated in (23) and (24), respectively.

$$
\begin{aligned}
& \mathbf{V}_{n}^{\text {iter }}= \begin{cases}\mathbf{X}_{r_{1}}^{\text {iter }}+\operatorname{rand} .\left(\mathbf{X}_{r_{2}}^{\text {iter }}-\mathbf{X}_{r_{3}}^{\text {iter }}\right) & \text { if rand } \leq 0.5 \\
\mathbf{X}_{r_{1}}^{\text {iter }}+\operatorname{rand} 1 .\left(\mathbf{X}_{r_{2}}^{\text {iter }}-\mathbf{X}_{r_{3}}^{\text {iter }}\right)+\operatorname{rand} 2 .\left(\mathbf{X}^{\text {best, iter }}-\mathbf{X}_{r_{4}}^{\text {iter }}\right) & \text { else }\end{cases} \\
& u_{m, j^{\prime}}^{\text {iter }}= \begin{cases}x_{m, j^{\prime}}^{\text {iter }} & \text { if rand } \leq 0.5 \\
v_{m, j^{\prime}}^{\text {iter }} & \text { else }\end{cases}
\end{aligned}
$$

where, $\mathbf{V}_{n}^{\text {iter }}$ is $\left[\begin{array}{lllll}v_{n, 1}^{\text {iter }} & \cdots & v_{n, j^{\prime}}^{\text {iter }} & \cdots & v_{n, N \mathrm{var}}^{\text {iter }}\end{array}\right] ; q_{n}^{\text {iter }}$ is the number of recently consecutive unsuccessful updates for the $n$th agent in iteration iter; rand is a random number between 0 and 1 , and $v_{m, j^{\prime}}^{i t e r}$ and $u_{m, j^{\prime}}^{i t e r}$ are the $j^{\prime}$ th element of 


\section{IET GENERATION, TRANSMISSION \& DISTRIBUTION}

vectors $\mathbf{V}_{n}^{\text {iter }}$ and $\mathbf{U}_{n}^{\text {iter }}$, respectively. The suggested strategy improves the process of selecting the mutant vectors through storing the successful agents into the archive $\mathbf{A}$, and selecting them from $\mathbf{A}$ when stagnation is happened. It should be mentioned that constraints (7)-(18) must be all satisfied during the IJA process. The following steps 1 and 2 are proposed to handle such requirement.

Step 1: Handling Inequality and Dynamic Constraints: If an element of the agent is infeasible, then it freezes to its boundary values. Thus, this process is defined as follows:

$$
\begin{aligned}
& g_{i, k, t}= \begin{cases}g_{i, k, t} & \text { if } \quad \underline{g}_{i, k, t} \leq g_{i, k, t} \leq \bar{g}_{i, k, t} \\
\underline{g}_{i, k, t} & \text { if } g_{i, k, t}<\underline{g}_{i, k, t} \\
\bar{g}_{i, k, t} & \text { if } g_{i, k, t}>\bar{g}_{i, k, t}\end{cases}
\end{aligned}
$$

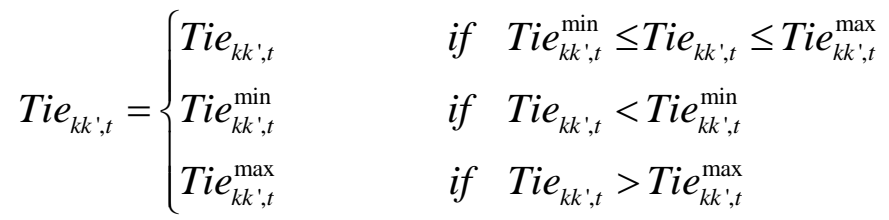

In addition, limitation (13) may be broken when the power output of a TU falls into its DPZs. In such circumstances, the power output of TU freezes to the closest lower or upper bounds of the DPZ. This process is formulated for the $i^{\text {th }} \mathrm{TU}$ in area $k$ when its generation is settled in its $\kappa$ th DPZ, $g_{i, k}^{L, \kappa}<g_{i, k, t}<g_{i, k}^{U, \kappa}$ as:

$$
g_{i, k}^{A v e, \kappa}=\frac{g_{i, k}^{L, \kappa}+g_{i, k}^{U, \kappa}}{2} \rightarrow g_{i, k, t}= \begin{cases}g_{i, k}^{L, \kappa} & \text { if } g_{i, k}^{L, \kappa}<g_{i, k, t} \leq g_{i, k}^{\text {Ave }, \kappa} \\ g_{i, k}^{U, \kappa} & \text { if } g_{i, k}^{\text {Ave }, \kappa}<g_{i, k, t}<g_{i, k}^{U, \kappa}\end{cases}
$$

Step 2: Handling Equality Constraints: The power balance feasibility in (7) and (8) should be first checked. The amount of power mismatch in each area can be calculated as follows:

$$
g_{k, t}^{v i o}=\sum_{i=1}^{N U K} g_{i, k, t}-\left(D_{k, t}+\operatorname{Loss}_{k, t}+\sum_{k^{\prime}=1, k^{\prime} \neq k}^{N K} T i e_{k k^{\prime}, t}\right)
$$

If $g_{k, t}^{v i o}=0$, return.

If $g_{k, t}^{v i o} \neq 0$, determine the areas that have non-zero power mismatch and select one randomly. Then randomly select one TU in this area and subtract the $g_{k, t}^{\text {vio }}$. If any TU breaches constraints (9)-(13), step 1 is called upon. Next, update the power loss formula using (8). If all the TUs are tested and $g_{k, t}^{v i o}$ is not yet zero, two TUs will be chosen as slack 


\section{IET GENERATION, TRANSMISSION \& DISTRIBUTION}

TUs and would share the $g_{k, t}^{v i o}$, and the same process goes on until all the areas meet their power balance requirements.

\subsection{Gradient-based Method (GM)}

One of the main features of the GM is its fast convergence. The strong exploitation capability of the GM is another feature that is employed to find the best solution in this study. If the best solution is improved by the GM, one can ensure that at least the near global Pareto optima have been obtained. In this context, the bi-objective Lagrange function is first formulated on the basis of (22) as follows:

$$
L^{g e r}=\omega_{1} \frac{F_{1}^{\max }-F_{1}(\mathbf{X})}{F_{1}^{\max }-F_{1}^{\min }}+\omega_{2} \frac{F_{2}^{\max }-F_{2}(\mathbf{X})}{F_{2}^{\max }-F_{2}^{\min }}+\lambda^{g e r} \sum_{k=1}^{N K}\left(D_{k, t}+\operatorname{Loss}_{k, t}+\sum_{k^{\prime}=1, k^{\prime} \neq k}^{N K} T i e_{k k^{\prime}, t}^{g e r}-\sum_{i=1}^{N U K} g_{i, k, t}^{g e r}\right)
$$

The gradient of this function is calculated as follows:

$$
\nabla L^{g e r}=\left[\begin{array}{l}
\frac{\partial L^{g e r}}{\partial g_{1,1, t}^{g e r}} \\
\vdots \\
\frac{\partial L^{g e r}}{\partial g_{N U K, N K, t}^{g e r}} \\
\frac{\partial L^{g e r}}{\partial T i e_{12, t}^{g e r}} \\
\vdots \\
\frac{\partial L^{g e r}}{\partial T i i_{N K-1 N K, t}^{g e r}} \\
\frac{\partial L^{g e r}}{\partial \lambda^{g e r}}
\end{array}\right]=\left[\begin{array}{l}
\frac{\omega_{1}}{F_{1}^{\min }-F_{1}^{\max }} \frac{\mathrm{d}}{\mathrm{d} g_{1,1, t}^{g e r}} F_{g}\left(g_{1,1, t}^{g e r}\right)+\frac{\omega_{2}}{F_{2}^{\min }-F_{2}^{\max }} \frac{\mathrm{d}}{\mathrm{d} g_{1,1, t}^{g e r}} F_{e}\left(g_{1,1, t}^{g e r}\right)+\lambda^{g e r}\left(\frac{\mathrm{d}}{\mathrm{d} g_{1,1, t}^{g e r}} \operatorname{Loss}_{1, t}-1\right) \\
\frac{\omega_{1}}{F_{1}^{\min }-F_{1}^{\max }} \frac{\mathrm{d}}{\mathrm{d} g_{N U K, N K, t}^{g e r}} F_{g}\left(g_{N U K, N K, t}^{g e r}\right)+\frac{\omega_{2}}{F_{2}^{\min }-F_{2}^{\max }} \frac{\mathrm{d}}{\mathrm{d} g_{1,1, t}^{g e r}} F_{e}\left(g_{N U K, N K, t}^{g e r}\right)+\lambda^{g e r}\left(\frac{\mathrm{d}}{\mathrm{d} g_{N U K, N K, t}^{g e r}} \operatorname{Loss}_{N K, t}-1\right) \\
\frac{\omega_{1}}{F_{1}^{\min }-F_{1}^{\max }} \frac{\mathrm{d}}{\mathrm{d} T i e_{12, t}^{g e r}} F_{T i e}\left(T i e_{12, t}^{g e r}\right)+\lambda^{g e r} \\
\frac{\mathrm{d}}{F_{1}^{\min }-F_{1}^{\max }} \frac{\mathrm{d} T i e_{N K-1 N K, t}^{g e r}}{\mathrm{~d}} F_{T i e}\left(T i e_{N K-1 N K, t}^{g e r}\right)+\lambda^{g e r} \\
\sum_{k=1}^{N K}\left(D_{k, t}+\operatorname{Loss}_{k, t}+\sum_{k^{\prime}=1, k^{\prime} \neq k}^{N K} \operatorname{Tie}_{k k^{\prime}, t}-\sum_{i=1}^{N U K} g_{i, k, t}\right)
\end{array}\right]
$$

It is noteworthy that the derivatives of $F_{g}\left(g_{i, k, t}^{g e r}\right)$ and $F_{e}\left(g_{i, k, t}^{g e r}\right)$ with respect to argument $g_{i, k, t}^{g e r}$ and derivative of $F_{T i e}\left(T i e_{k k, t}^{g e r}\right)$ with respect to $T i e_{k k, t}^{g e r}$ are computed as follows:

$$
\begin{aligned}
& \frac{\mathrm{d}}{\mathrm{d} g_{i, k, t}^{\text {ger }}} F_{g}\left(g_{i, k, t}^{\text {ger }}\right)=b_{i, k}^{n f_{i}}+2 c_{i, k}^{n f_{i}} g_{i, k, t}^{g e r}+\frac{\left(-e_{i, k}^{n f_{i}} d_{i, k}^{n f_{i}} \cos \left(e_{i, k}^{n f_{i}}\left(g_{i, k}^{\min }-g_{i, k, t}^{g e r}\right)\right)\right)\left(d_{i, k}^{n f_{i}} \sin \left(e_{i, k}^{n f_{i}}\left(g_{i, k}^{\min }-g_{i, k, t}^{g e r}\right)\right)\right)}{\left|d_{i, k}^{n f_{i}} \sin \left(e_{i, k}^{n f_{i}}\left(g_{i, k}^{\min }-g_{i, k, t}^{\text {ger }}\right)\right)\right|} \\
& \frac{\mathrm{d}}{\mathrm{d} T i e_{k k^{\prime}, t}} F_{T i e}\left(T i e_{k k^{\prime}, t}^{g e r}\right)=c_{k k^{\prime}}
\end{aligned}
$$


$\frac{\mathrm{d}}{\mathrm{d} g_{i, k, t}^{g e r}} F_{e}\left(g_{i, k, t}^{g e r}\right)=\beta_{i, k}+2 \gamma_{i, k} g_{i, k, t}^{g e r}+\lambda_{i, k} \zeta_{i, k} \exp \left(\zeta_{i, k} g_{i, k, t}^{g e r}\right)$

By applying the differentiation formula for the absolute sinusoidal cost function and exponential emission function, their derivatives are respectively formulated in (31) and (33). They are graphically illustrated in Fig. 3(a), (b) and Fig.3(c), (d) corresponding to the two TUs for which the original functions' surface are shown in Fig. 1. It is clearly demonstrated that although the first absolute sinusoidal function is continuous in Fig. 1 (a), it is not differentiable at all points. As shown in (31) and Fig. 3 (a)-(b), there might be a TU for which the term $d_{i, k}^{n f_{i}} \sin \left(e_{i, k}^{n f_{i}}\left(g_{i, k}^{\min }-g_{i, k, t}^{g e r}\right)\right)$ in its derivative function would be equal to zero. This implies that the derivative is not defined when $d_{i, k}^{n f_{i}} \sin \left(e_{i, k}^{n f_{i}}\left(g_{i, k}^{\min }-g_{i, k, t}^{g e r}\right)\right)=0$. If $e_{i, k}^{n f_{i}}\left(g_{i, k}^{\min }-g_{i, k, t}^{g e r}\right) \in\{2 n \pi,(2 n+1) \pi\}$, where $n$ is an integer number, then the derivative does not exist. Therefore, such points are fixed to their generation levels obtained from the IJA and remain fixed during the GM procedure. For the differentiable points, for which $e_{i, k}^{n f_{i}}\left(g_{i, k}^{\min }-g_{i, k, t}^{g e r}\right) \in(2 n \pi,(2 n+1) \pi)$ and $((2 n+1) \pi,(2 n+2) \pi)$ is valid, the new agent in iteration ger of the GM is calculated as follows:

$$
\left[\begin{array}{l}
g_{1,1, t}^{\text {ger }} \\
\vdots \\
g_{N U K, N K, t}^{\text {ger }} \\
\operatorname{Ti}_{12, t}^{g e r} \\
\vdots \\
\operatorname{Tie}_{N K-1 N K, t}^{\text {ger }} \\
\lambda^{\text {ger }}
\end{array}\right]=\left[\begin{array}{l}
g_{1,1, t}^{\text {ger }-1} \\
\vdots \\
g_{N U K, N K, t}^{\text {ger }-1} \\
T i e_{12, t}^{g e r-1} \\
\vdots \\
T i e_{N K-1 N K, t}^{\text {ger } 1} \\
\lambda^{\text {ger }-1}
\end{array}\right]+\alpha^{g e r}\left[\begin{array}{l}
\Delta g_{1,1, t}^{g e r} \\
\vdots \\
\Delta g_{N U K, N K, t}^{g e r} \\
\Delta T i e_{12, t}^{g e r} \\
\vdots \\
\Delta T i e_{N K-1 N K, t}^{g e r} \\
\Delta \lambda^{g e r}
\end{array}\right]
$$

Where, 


$$
\left[\begin{array}{l}
\Delta g_{1,1, t}^{\text {ger }} \\
\vdots \\
\Delta g_{N U K, N K, t}^{\text {ger }} \\
\Delta T i e_{12, t}^{g e r} \\
\vdots \\
\Delta T i e_{N K-1 N K, t}^{g e r} \\
\Delta \lambda^{g e r}
\end{array}\right]=m^{g e r}\left[\begin{array}{l}
\Delta g_{1,1, t}^{\text {ger }-1} \\
\vdots \\
\Delta g_{N U K, N K, t}^{\text {ger } 1} \\
\Delta T i e_{12, t}^{g e r-1} \\
\vdots \\
\Delta T i e_{N K-1 N K, t}^{g e r-1} \\
\Delta \lambda^{g e r-1}
\end{array}\right]+\left(1-m^{g e r}\right) \nabla L^{g e r}
$$

where, $m^{g e r}$ and $\alpha^{\text {ger }}$ are the GM parameters which can be updated as follows [35]:

If $L^{\text {ger }}<L^{\text {ger-1 }}$

$m^{\text {ger }}=0.8 ; \alpha^{\text {ger }}=1.1 \alpha^{\text {ger-1 }}$

Else

$m^{\text {ger }}=0 ; \alpha^{\text {ger }}=0.9 \alpha^{\text {ger-1 }}$

End

\section{Figure3}

\section{Bi-objective Optimization Methodology}

In this study, MBED is formulated as a bi-objective optimization problem (BOP). Generally in such optimization formulations, no single solution is capable of simultaneously optimizing both objective functions. In this case, different Pareto optimal (also known as non-dominated) solutions may exist. It is called Pareto optimal as the solution worsens the condition of at least one objective function while improving the others. The optimization process would then select the most preferable solution through trade-offs. The bi-objective optimization approach has been introduced as an appropriate tool for handling incommensurable objectives with conflicting/supporting relations. As the problem dimension increases, it becomes infeasible to reach the global or near-global Pareto optimal solutions in which both objectives can be optimized simultaneously. Different methods are introduced in the literature to deal with such bi-objective optimization problems which can be classified to priori and posterior techniques [36], [37].

1) In priori frameworks, such as weighted sum method or $\varepsilon$-constraint algorithm, a relative preference matrix should be provided with minimum knowledge on the possible outcomes. Thus, the preference matrix may 


\section{IET GENERATION, TRANSMISSION \& DISTRIBUTION}

lead to a suboptimal consequence or an infeasible outcome. It is notable that this is extremely subjective to the TSO as the decision maker. Additionally, they may not only be a time-consuming and monotonous process, but also may lead to recurrence of the non-dominated solutions so that a good Pareto optimal curve might not be achieved [38]. Therefore, normal boundary intersection [38] and normalized normal constraint method [39] are developed to obtain a diverse and spread Pareto set. However, such methods involve handling the single optimization problem per Pareto point created. In other words, it mandates applying a numerical optimizer for solving the Pareto optimal points. Furthermore, the optimizer should work with a highly constrictive feasible sphere including a single line in three-dimensional space. In an extremely complicated optimization problem such as the MBED at hand, this may lead the optimizer to never discover its way back to the feasible area and therefore no true or near optimal Pareto frontier can be ever established. In addition, the CPU execution time of the normal boundary intersection technique increases in a larger rate with the growth in the number of decision variables, restrictions and of course number of Pareto optimal points to be extracted [40].

2) In contrast, the goal of posterior techniques is to find the Pareto-optimal solutions using the non-dominancy conceptions. All such optimal solutions can be fed into the decision making framework in order to find the final optimal solution considering the TSO's preferences [41]. Albeit the population-based techniques such as the non-dominated sorting genetic algorithm-II (NSGA-II) [42] and multi-objective particle swarm optimization (MOPSO) [43] technique can provide the entire Pareto optimal front all-at-once, they suffer from tuning of numerous algorithmic parameters for a suitable optimization process. For instance, the NSGA-II mandates setting up several parameters including the crossover type, its probability, mutation probability, etc. The MOPSO also needs to tune the cognitive parameter, social parameter, initial inertia weight factor, and final inertia weight factor. Consequently, the JA which is known as the algorithmicparameter free of tuning technique is selected. Additionally, due to the heuristic nature of such algorithms, the same Pareto optimal solution is often not regenerated. In this paper, the heuristic-based mutation strategy and the mathematical-based GM can provide a balance between the global and local search characteristics of the IGJA and help to return the robust, fast and optimal solution in one trial run. The statistical evidence of producing such Pareto optimal fronts with acceptable execution time is provided in the next Section. 
In general, the BOP is mathematically described as follows [14], [15]:

\section{Min $F(\mathbf{X})$}

\section{Subject to}

$$
\begin{aligned}
& G_{e q}(\mathbf{X})=0 \\
& H_{\text {ine }}(\mathbf{X}) \leq 0
\end{aligned}
$$

where,

$$
\begin{gathered}
F(\mathbf{X})=\left[F_{1}(\mathbf{X}), F_{2}(\mathbf{X})\right] \\
e q=1, \ldots, \text { Neq } \\
\text { ine }=1, \ldots, \text { Nine }
\end{gathered}
$$

In (36) and (37), $F(\mathbf{X})$ represents the vector of objective functions with two elements, $G_{e q}(\mathbf{X})$ function of the $e q^{\text {th }}$ equality constraint, $H_{\text {ine }}(\mathbf{X})$ function of the ine $e^{\text {th }}$ inequality constraint, and $N e q$ and Nine the numbers of equality and inequality constraints, respectively. $\mathbf{X}^{*}$ is a Pareto optimal solution of the minimization problem defined by (36) if the following two conditions are valid for any $\mathbf{X} \in \Omega-\left\{\mathbf{X}^{*}\right\}$ in the search space of $\Omega$ :

$\forall o b j \in\{1,2\} \quad F_{o b j}\left(\mathbf{X}^{*}\right) \leq F_{o b j}(\mathbf{X})$

and

$\exists o b j^{\prime} \in\{1,2\} F_{o b j^{\prime}}\left(\mathbf{X}^{*}\right)<F_{o b j^{\prime}}(\mathbf{X})$

In order to select the best compromised solution out of a set of non-dominated points, a fuzzy decision making procedure is proposed. Let's assume that there are NRep different non-dominated solutions in the repository of the BOP. To implement this procedure for $r^{\text {th }}$ Pareto optimal solution $\mathbf{X}_{r}^{*}(r \in\{1, \ldots, N R e p\})$, the $\mu_{o b j}\left(\mathbf{X}_{r}^{*}\right)$ is first calculated in (21). Using this pseudo-objective value and corresponding weighting factor, the normalized membership index $\left(\varpi_{o b j}\right)$ for $\mathbf{X}_{r}^{*}$ is defined as follows [15]:

$$
\varpi_{o b j}=\frac{\sum_{o b j=1}^{2} \omega_{o b j} \mu_{o b j}\left(\mathbf{X}_{r}^{*}\right)}{\sum_{r=1}^{N R e p} \sum_{o b j=1}^{2} \omega_{o b j} \mu_{o b j}\left(\mathbf{X}_{r}^{*}\right)}
$$




\section{IET GENERATION, TRANSMISSION \& DISTRIBUTION}

where, $\omega_{o b j}$ is the weighting factor assigned to $o b j^{\text {th }}$ objective function. It should be pointed out that the candidate with the maximum value of $\varpi_{o b j}$ is the best compromised solution. The block diagram of the suggested bi-objective IGJA approach describing the overall process is shown in Fig. 4.

\section{Figure 4}

\section{Simulation Results}

\subsection{Test Systems and Parameters Adjustments}

In order to examine the effectiveness and capability of the suggested IGJA, the multi-area mono-objective economic dispatch (MED1), multi-area mono-objective emission dispatch (MED2), and MBED problems with respective mono-, mono- and bi-objective functions are solved for five standard test systems with different number of areas, TUs, and constraints. The test system characteristics referring to MED1, MED2, MBED, transmission cost, valvepoint effect, DPZ, multiple fuel option, transmission line losses, up/down ramp rate and reserve restrictions, values of $N K, N U K$ and $D_{k, t}$ are presented in Table 1.

In case of the MED1 and MED2, the quality of the final solutions is assessed using the best, mean, worst, CPU computation time and convergence graph. The best, mean, and worst provide an outline of the concentration corresponding to the extracted solutions during 30 trial runs with respect to the central point of the distribution.

\section{Table1}

\subsection{Test System 1: 2 Areas with 6 TUs}

This renowned test system comprises of two areas with 6 TUs for which the data is taken from [19] and [20]. The MED1 is solved by IGJA and compared to the original JA and several recently presented algorithms such as Real Coded Genetic Algorithm (RCGA) [20], Evolutionary Programming (EP) [20], Differential Evolution (DE) [20], Artificial Bee Colony Optimization (ABCO) [20], Teaching-Learning-Based Optimization (TLBO) [19], and Chaotic Global Best Artificial Bee Colony (CGBABC) [23]. The results of the best solution are illustrated in Table 2. Almost all the techniques yield a comparable near-global optimum due to low dimension of this test system. The reported value for the system total loss is smaller than that in recent literature CGBABC [23], i.e. (13.6159 MW vs. 13.6161 MW). Moreover, the optimal power schedules of TUs and tie-lines in the cases of neglecting DPZs and 


\section{IET GENERATION, TRANSMISSION \& DISTRIBUTION}

losses using IGJA are also reported in this Table. It is concluded that the network losses and objective functions may force the TUs of each area to generate electric power in different sub feasible zones. It is clear that ignoring such practical constraints would change the design variables and decreases the system operation cost leading to an inaccurate decision making by the TSO. Furthermore, the best, mean and worst solutions provided by IGJA are equal reflecting the fact that the IGJA is robust enough to provide equal solutions for 30 trial runs. According to the CPU computation time, the presented algorithm can provide the output solution much faster than others. More importantly, if the output design variables of CGBABC are recalculated by (2), then the resultant cost marginally differs from the reported costs which are shown in Table 2. Albeit there are minor power mismatches in the results of CGBABC, the proposed technique can provide more robust and fast solutions with no mismatch which is actually due to hybridizing the GM as a mathematical-based technique and heuristic-based IJA.

Fig. 5(a) shows the convergence graph of IGJA and original JA applications to this test system. It is strikingly observed that the convergence is reached in a considerably less number of iterations which leads to a reasonable execution time. It is also remarkable that the JA is susceptible to get stuck into local optima as it does not employ the mutation and GM strategies.

\section{Table2}

\section{Figure5}

\subsection{Test System 2: 3 Areas with 10 TUs}

This test system includes three areas with 10 TUs for which the data is given in [20]. The MED1 is solved by IGJA and compared to other state-of-the-art optimization approaches such as RCGA [20], EP [20], DE [20], ABCO [20], TLBO [19] and CGBABC [23] in Table 3. In addition, the results associated with the cases where network losses are neglected are appended to this Table for the sake of comparison. While the improvement in the best operation cost is only marginal in comparison with various techniques presented in recent literature, the suggested IGJA is definitely more robust. Unlike the developed algorithm, some of the other well-known algorithms are unsuccessful to perform constantly well as exposed in Table 3. As advocated for some heuristic methodologies which are stripped of convergence assurances, the proposed IGJA with the aid of GM is competent enough to converge to the near-global and acceptable solution. In other words, apart from being robust and fast, the suggested algorithm can converge to 


\section{IET GENERATION, TRANSMISSION \& DISTRIBUTION}

the near-global optimum within 8 iterations, as portrayed in Fig. 5 (b). The suggested mutation strategy along with the GM can provide a balance between the diversity and convergence rate or diversification and intensification capacities of the IGJA which is an apparently critical requirement in providing a quality solution.

\section{Table3}

\subsection{Test System 3: 4 Areas with 16 TUs}

This test case considers two types of 4-area 16-unit systems for which the characteristic, data, TUs and tie-line constraints are borrowed from [17], [23] and [24]. Unlike the previous test cases, all three problems, i.e., MED1, MED2, and MBED, are solved to comparatively check the efficiency of the projected IGJA. Tables 4 to 6 presents a comparison of the results provided by IGJA with those achieved with other techniques presented in the state-of-theart literature in three cases; case1: first 16-unit system; case2: second 16-unit system neglecting valve-point effect; and case3: second 16-unit system considering valve-point effect. Different scenarios are taken into account in this case study to clarify the superiority of the projected method in satisfying different types of restrictions and constraints. In order to incorporate the valve-point effects of TUs, the optimal generation outputs of TUs are changed resulting to an increase in operation cost as well as emission growth $[(\$ 2,127.5925$ and 5.78778 ton $)$ to ( $\$ 2,235.99277$ and 5.81572 ton)] for the second test case. One can see that the suggested IGJA can still provide better results with the highest rate of execution efficiency compared to other algorithms especially in case of considering hard constraints. In general, the meta-heuristic algorithms are on the basis of population and, therefore, the optimal candidate solution may change in different simulations, while the GM is a mathematical-based technique and is able to dramatically enhance the robustness of the selection process. Additionally, it can theoretically guarantee the near global optimality of the proposed algorithm in shorter time. Besides, with the enhanced simulation time of the proposed approach, the CPU computation time is much better than others for all the studied optimization problems.

As the boundary points of the trade-off surface are provided, the MBED problem is solved to achieve the Pareto frontier. This curve allows the TSO to have the databank of several non-dominated solutions between the probable optimal operation cost and the possible optimal environmental effect. Figs. 6(a), (b), (c) bear witness to the attribute development of the suggested technique and displays the Pareto optimal frontiers obtained by the IGJA for three abovementioned cases. As shown, the IGJA struggles to keep up the uniformity and smoothness of the solutions 


\section{IET GENERATION, TRANSMISSION \& DISTRIBUTION}

along the curve, especially around the edges. However, the Pareto frontier of the first case study which is portrayed in Fig. 6. (a) is not uniform. This benchmark bi-objective test problem (case1) is selected to explore different characteristics, e.g., tie-line cost (Table 1) and discontinuity in the shape of true Pareto front. In order to further clarify, the NSGA-II [42] and MOPSO [43] techniques are also employed in this case study for which the results are demonstrated in Fig. 7. It is clear that the aforementioned two algorithms have resulted in a discontinuity in their Pareto curves. Moreover, they fail to discover the extreme points of the Pareto surface and the optimal nondominated points are more crowded in other parts rather than the edges.

The best compromised solutions of the above cases (Fig. 6) are listed in Tables 4 to 6 in which all the solutions have lower operation cost as well as emissions compared to other well-known algorithms such as [case1: (IGJA: $\$ 6,697.69791$ and 7,471.11752 ton) vs. (CGBABC [23]: \$9,569.40579 and 7,227.110436 ton); case2: (IGJA: $\$ 2,137.68910$ and 3.45047 ton) vs. (CASE I [22]: \$2,152.21264 and 4.65918 ton); and case3: (IGJA: \$2,151.69601 and 3.02967 ton) vs. (CASE I [22]: \$2,161.6991 and 3.08730 ton)]. Furthermore, the CPU simulation run time of the IGJA is enhanced with respect to CGBABC [23] and CASE I [22].

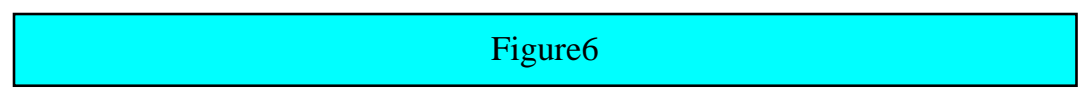

\section{Figure7}

\section{Tables4 to 6}

\subsection{Test System 4: 4 Areas with 40 TUs}

This test system consists of 40 TUs which are equally distributed in 4 areas. The problem search terrain of this test system is characterized by uncountable local minimum points. To efficiently tackle such hard problems, the proposed IGJA is applied on MED1 and MED2 and the results are compared with other state-of-the-art approaches in Table 7. As one can infer from this Table, although other techniques might seldom provide an optimal solution which is near to that of the suggested one, the IGJA returns the robust, fast and optimal solution in one trial run. In order to verify the superiority of the suggested bi-objective methodology, the IGJA is implemented to derive the Pareto solution frontiers in two different cases with and without DPZs considerations (Fig. 8(a), (b)). The Pareto optimal surfaces of both subcases achieved by utilizing the IGJA have great diversity and distribute uniformly in 
two dimensions space. The figure illustrates that the proposed algorithm can provide the near global non-dominated solutions within 30 iterations, so rendering a practical and scalable alternative strategy.

\section{Table7}

\section{Figure8}

\subsection{Test System 5: 2 Areas with 120 Units}

In order to further confirm the applicability and scalability of the suggested IGJA, a practical case with enormous 120 units is considered that aggravate the hurdles of optimization procedure. In concordance with the previous results for four test cases, the proposed IGJA minimizes the operation cost outstandingly superior in the MED1 problem. The corresponding results in 30 trial runs are noticeably less than JA and IJA and also compared with the results of classical optimization program (CM) [44] and GBABC [23] in Table 8. In addition to the impressive outputs, there is a competency in the capability of the suggested technique to converge to a solution with quality properties. This claim is clarified by the convergence characteristic in Fig. 8(c) where one can confirm that the IGJA can quickly converge to an optimal and robust solution. While it is almost advocated for meta-heuristic approaches that they are deprived of a convergence guarantee, suffering from the premature convergence and entrapping in local optima, the proposed IGJA puts the JA, mutation strategy, and GM together to successfully surpass the original JA, escape from local optima, and eventually halt to an acceptable solution in all 30 trial runs.

\section{Table8}

\section{Conclusion}

The IGJA algorithm hybridizes the GM, JA and mutation strategies and has been set up in this study to more accurately solve the complex MBED problems with practical constraints on several small and large scale test systems. Recall that on one hand, the bi-objective GM is introduced with deep-seated mathematical characteristics appropriate for improving the robustness of the main algorithm. With respect to other approaches that use Lagrange relaxation concept, the proposed method competitively considered the lambda as the decision variable for the JA. On the other hand, JA is known for its algorithmic-parameter free of tuning. In this paper, a new mutation strategy is integrated in the JA to enhance its exploitation and exploration, simultaneously. Moreover, the proposed Paretobased bi-objective approach was proved that does not deteriorate when confronted with multimodal and deceptive 


\section{IET GENERATION, TRANSMISSION \& DISTRIBUTION}

problems. The effectiveness, flexibility and scalability of the suggested algorithm were verified by the complexity and convergence analysis as well as experimental studies. The developed framework can be also employed in other combinatorial bi objective optimization problems within the electric power system domain such as optimal power flow, unit commitment, etc.

\section{References}

[1] Farag, A., Al-Baiyat, S., Cheng, T.C.: 'Economic load dispatch multiobjective optimization procedures using linear programming techniques', IEEE Trans. Power Syst., 2007, 1, (2), pp. 731-738

[2] Palanichamy, C., Sundar Babu, N.: 'Analytical solution for combined economic and emissions dispatch', Electr. Power Syst. Res., 2008, 78, (7), pp. 1129-1137

[3] Shin-Der, C., Jiann-Fuh, C.: 'A direct Newton-Raphson economic emission dispatch’, Int. J. Electr. Power Energy Syst., 2003, 25, (5), pp. 411-417

[4] Streiffert, D.: 'Multi-area economic dispatch with tie line constraints', IEEE Trans. Power Syst., 1995, 10, (4), pp. 1946-1951

[5] Yingvivatanapong, C., Wei-Jen, L., Liu, E.: 'Multi-area power generation dispatch in competitive markets', IEEE Trans. Power Syst., 2008, 23, (1), pp. 196-203

[6] Ding, T., Bo, R., Gu, W., et al.: 'Big-M based MIQP method for economic dispatch with disjoint prohibited zones, IEEE Trans. Power Syst., 2014, 29, (2), pp. 976-977

[7] Vaccaro, A., Loia, V., Formato, G., et al.: 'A self-organizing architecture for decentralized smart microgrids synchronization, control, and monitoring, IEEE Trans. Ind. Informat., 2015, 11, (1), pp. 289-298

[8] Loia, V., Terzija, V., Vaccaro, A., et al.: 'An affine-arithmetic-based consensus protocol for smartgrid computing in the presence of data uncertainties. IEEE Trans. Ind. Electronics, 2015, 62, (5), pp. 2973-8292

[9] Loia, V., Vaccaro, A.: 'Decentralized economic dispatch in smart grids by self-organizing dynamic agents', IEEE Trans. Syst., Man, Cybern. Syst., 2014, 44, (4), pp. 397-408

[10]Elsayed, W.T., El-Saadany, E.F.: 'A fully decentralized approach for solving the economic dispatch problem', IEEE Trans. Power Syst., 2015, 30, (4), 2179-2189 


\section{IET GENERATION, TRANSMISSION \& DISTRIBUTION}

[11]Liu, X.: 'On compact formulation of constraints induced by disjoint prohibited-zones', IEEE Trans. Power Syst., 2010, 25, (4), pp. 2004-2005

[12]Jabr, R.A.: 'Solution to economic dispatching with disjoint feasible regions via semi-definite programming', IEEE Trans. Power Syst., 2012, 27, (1), pp. 572-573

[13] Panigrahi, B.K., Pandi, V.R.: 'Bacterial foraging optimisation: Nelder-Mead hybrid algorithm for economic load dispatch', IET Gener. Transm. Distrib., 2008, 2, (4), pp. 556-565

[14] Agrawal, S., Panigrahi, B.K., Tiwari, M.K.: 'Multiobjective particle swarm algorithm with fuzzy clustering for electrical power dispatch', IEEE Trans. Evol. Comput., 2008, 12, (5), pp. 529-541

[15] Abido, M.A.: 'Multiobjective evolutionary algorithms for electric power dispatch problem', IEEE Trans. Evol. Comput., 2006, 10, (3), pp. 315-329

[16] Jadoun, V.K., Gupta, N., Niazi, K.R., Swarnkar, A.: 'Multi-area economic dispatch with reserve sharing using dynamically controlled particle swarm optimization', Int. J. Electr. Power Energy Syst., 2015, 73, pp. 743-756

[17]Fesanghary, M., Ardehali, M.M.: 'A novel meta-heuristic optimization methodology for solving various types of economic dispatch problem', Energy, 2009, 34, (6), pp. 757-766

[18] Jadoun, V.K., Gupta, N., Niazi, K.R., et al.: 'Multi-area economic dispatch using improved particle swarm optimization, Energy Procedia, 2015, 75, pp. 1087-1092

[19]Basu, M.: 'Teaching-learning-based optimization algorithm for multi-area economic dispatch', Energy, 2014, 68, pp. 21-28

[20] Basu, M.: ‘Artificial bee colony optimization for multi-area economic dispatch', Int. J. Electr. Power Energy Syst., 2013, 49, pp. 181-187

[21] Jeyakumar, D.N., Jayabarathi, T., Raghunathan, T.: 'Particle swarm optimization for various types of economic dispatch problems, Int. J. Elect. Power Energy Syst., 2006, 28, (1), pp. 36-42

[22] Pandit, M., Srivastava, L., Sharma, M.: 'Environmental economic dispatch in multi-area power system employing improved differential evolution with fuzzy selection', Applied Soft Computing, 2015,28 , pp. $498-510$

[23] Secui, D.C.: 'The chaotic global best artificial bee colony algorithm for the multi-area economic/emission dispatch', Energy, 2015, 93, 2518-2545 
[24] Wang, L., Singh, C.: 'Reserve-constrained multiarea environmental/economic dispatch based on particle swarm optimization with local search', Eng. Appl. Artific. Intel., 2009, 22, (2), pp. 298-307

[25]Lee K., and El-Sharkawi, M.: 'Modern heuristic optimization techniques: Theory and applications to power systems’ (John Wiley \& Sons Press, New York, 1st edn. 2008)

[26] Rao, R.: 'Jaya: A simple and new optimization algorithm for solving constrained and unconstrained optimization problems', Int. J. Ind. Eng. Comput., 2016, 7, (1), pp. 19-34

[27] Kron, G.: 'Tensorial analysis of integrated transmission systems; Part II. Off-nominal turn ratios', Power App. Syst. III. Trans. Amer. Inst. Elect. Eng., 1952, 71, pp. 505-512

[28] Wood, A.J., and Wollenberg, B.F.: 'Power generation, operation, and control' (John Wiley \& Sons Press, New York, 1996, $2^{\text {nd }}$ Edn. 2012)

[29] Kirchmayer, L.K., Stagg, G.W., 'Analysis of total and incremental losses in transmission systems', Trans. American Institute Electric. Eng., 1951, 70, (2), pp. 1197-1205

[30] Kron, G.: 'Tensorial analysis of integrated transmission systems; Part IV. the interconnection of transmission systems [includes discussion]', Trans. American Institute Electric. Eng. Power App. Syst. Part III., 1953 72, (2)

[31] Soliman, S.A.-H., Mantawy, A.-A.H.: 'Modern optimization techniques with applications in electric power systems (energy systems)', (Springer, Berlin, Germany, 2011)

[32]Zheng, W., Wu, W., Zhang, B., et al.: 'Fully distributed multi-area economic dispatch method for active distribution networks, IET Gener. Transm. Distrib., 2015, 9, (12), pp. 1341-1351

[33] Lee, F.N., Breipohl, A.M.: 'Reserve constrained economic dispatch with prohibited operating zones', IEEE Trans. Power Syst., 1993, 8, (1), pp. 246-254

[34] Wang, S.K, Chiou, J.P., Liu, C.W.: 'Non-smooth/non-convex economic dispatch by a novel hybrid differential evolution algorithm', IET Gener., Transm. Distrib., 2007, 1, (5), pp. 793-803

[35] Hagan, M.T., Dcmuth, H.B., and Beale, M.: 'Neural network design’ (PWS Publishing Company, USA, 1st edn. 1996)

[36]Deb, K.: 'Multi-objective optimization using evolutionary algorithms' (John Wiley \& Sons Press, New York, 2003) 


\section{IET GENERATION, TRANSMISSION \& DISTRIBUTION}

[37] Mendoza, F., Bernal-Agustin, J.L., Dominguez-Navarro, J. A.: 'NSGA and SPEA applied to multiobjective design of power distribution systems', IEEE Trans. Power Syst., 2006, 21, (4), pp. 19381945

[38] Das, I., Dennis, J.: 'Normal boundary intersection: a new method for generating Pareto surface in nonlinear multicriteria optimization problems', SIAM J. Optim., 1998, 8, (3), pp. 631-657

[39] Messac, A., Ismail-Yahaya, A., Mattson, C.A.: 'The normalized normal constraint method for generating the Pareto frontier,' Struct. Multidisc. Optim., 2003, 25, (2), pp. 86-98

[40] Siddiqui, S., Azarm, S., Gabriel, S.A.: 'On improving normal boundary intersection method for generation of Pareto frontier', Struct Multidisc. Optim., 2012, 46, (6), pp. 839-852

[41] Yao, J., Kharma, N., Grogono, P.: 'Bi-objective multipopulation genetic algorithm for multimodal function optimization', IEEE Trans. Power Syst., 2010, 14, (1), pp. 80-102

[42] Abido, M.A.: 'Multiobjective evolutionary algorithms for electric power dispatch problem', IEEE Trans. Evol. Comput., 2006, 10, (3), pp. 315-329

[43] Agrawal, S., Panigrahi, B.K., Tiwari, M.K.: 'Multiobjective particle swarm algorithm with fuzzy clustering for electrical power dispatch', IEEE Trans. Evol. Comput., 2008, 12, (5), pp. 529-541

[44] Yalcinoz, T., Short, M.J.: 'Neural networks approach for solving economic dispatch problem with transmission capacity constraints', IEEE Trans. Power Syst., 1998, 13, (2), pp. 307-313 


\section{Figure Captions}

Figure 1. (a) and (b): Surface of the sinusoidal and quadratic cost functions of a 2-unit system in a typical area, respectively; (c) and (d): Surface of the exponential and quadratic emission functions of a 2-unit system in a typical area, respectively.

Figure 2. (a) Diagram for the sub-feasible regions of three units and their feasible solution planes; (b) Spinning reserve of a typical TU with and without considering DPZs.

Figure 3. (a) and (b): First order derivations of the first and second units' fuel cost functions, respectively; (c) and (d) First order derivations of the first and second units' emission functions.

Figure 4. Flowchart of the proposed bi-objective IGJA.

Figure 5. Convergence graph of the proposed IGJA compared to JA for (a) test system 1, (b) test system 2.

Figure 6. Pareto frontier of the proposed IGJA for (a) test system 3, Case1, (b) test system 3, Case2, and (c) test system 3, Case3.

Figure 7. Pareto frontiers obtained by proposed IGJA, MOPSO and NSGA-II for test system 3, Case1.

Figure 8. (a) and (b) Pareto frontiers found by the proposed IGJA for test system 4 with/without considering DPZs and (c) Convergence graph of the proposed IGJA compared to JA for test system 5. 


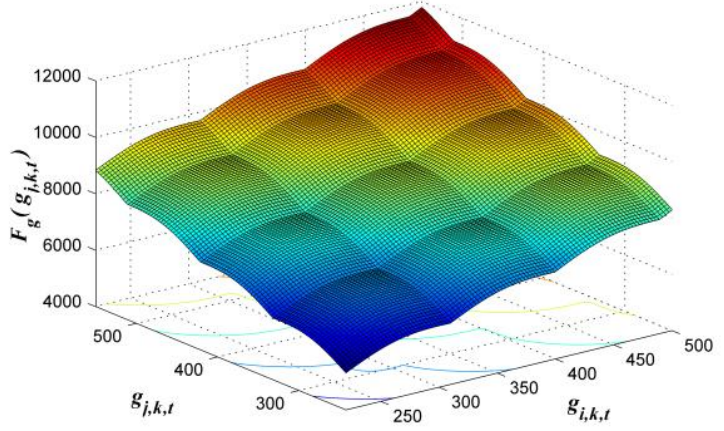

a)

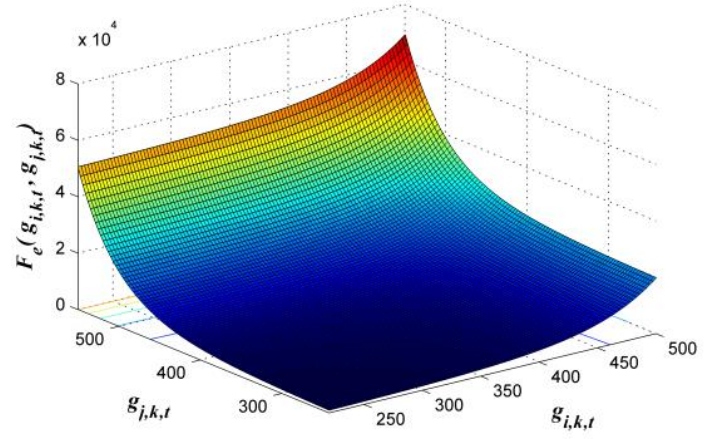

c)

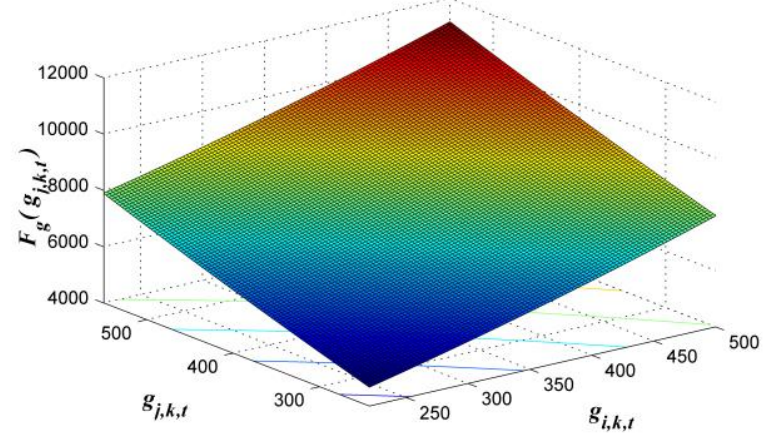

b)

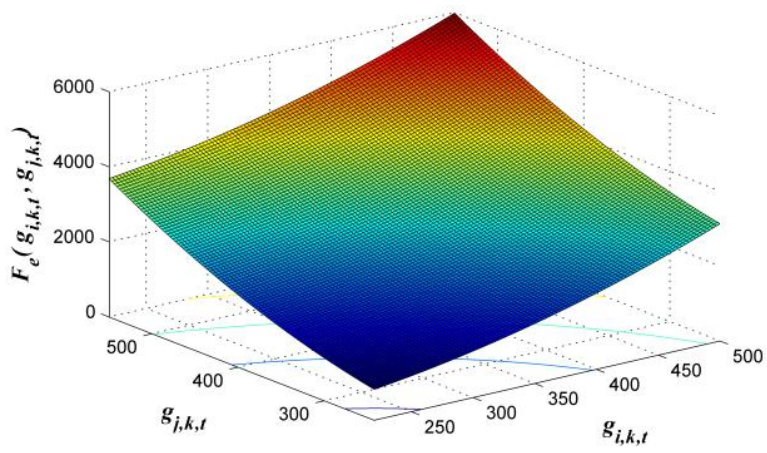

d)

Fig. 1. (a) and (b): Surface of the sinusoidal and quadratic cost functions of a 2-unit system in a typical area, respectively; (c) and (d): Surface of the exponential and quadratic emission functions of a 2-unit system in a typical area, respectively.

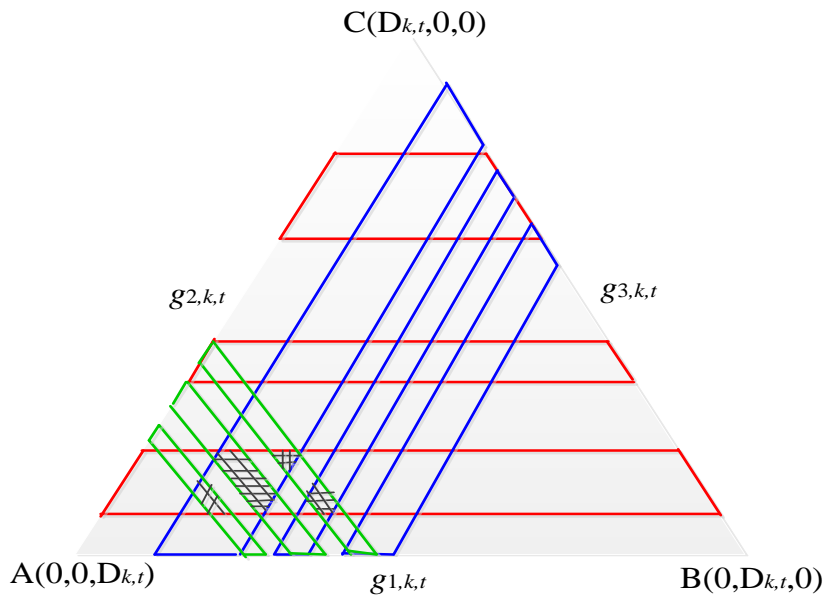

a)

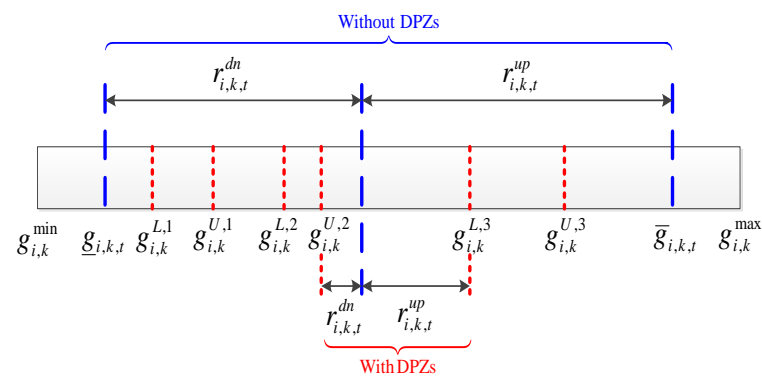

b)

Fig. 2. (a) Diagram for the sub-feasible regions of three units and their feasible solution planes; (b) Spinning reserve of a typical TU with and without considering DPZs. 


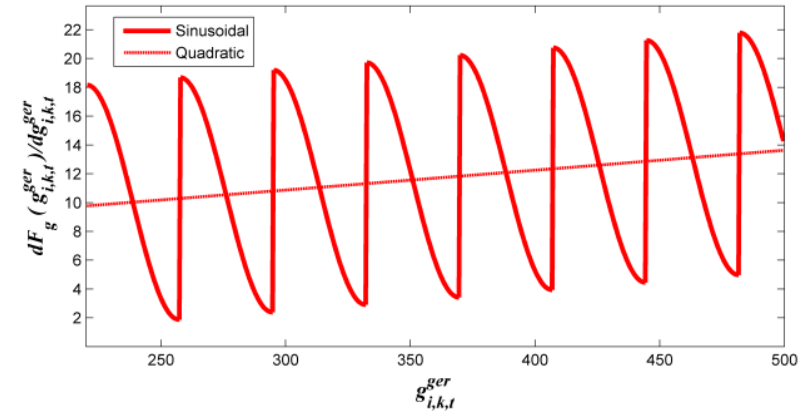

a)

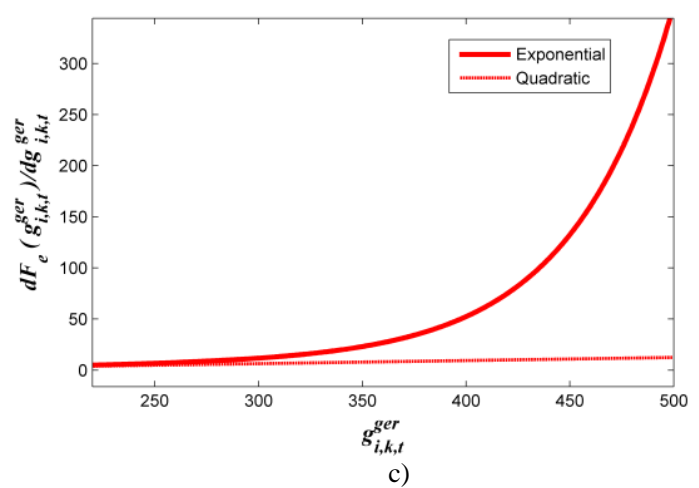

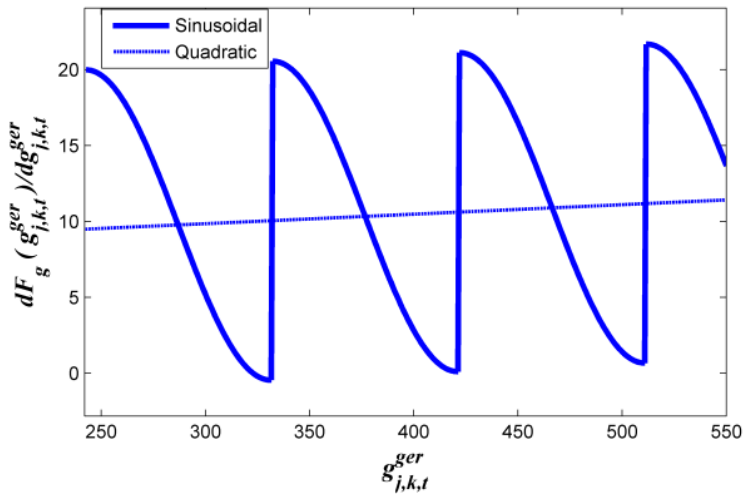

b)

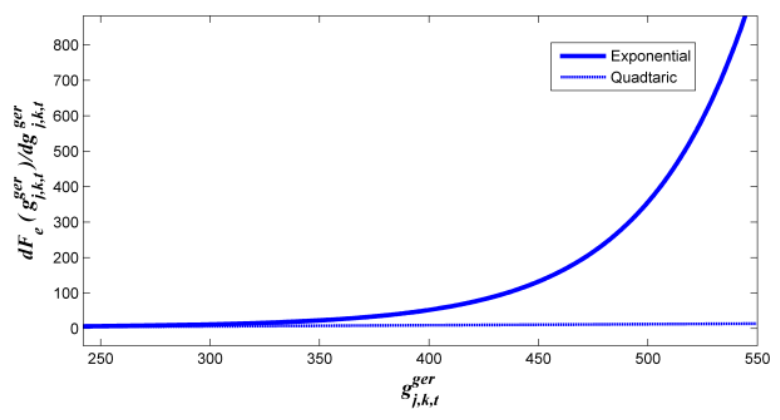

d)

Fig. 3. (a) and (b): First order derivations of the first and second units' fuel cost functions, respectively; and (c) and (d) First order derivations of the first and second units' emission functions. 


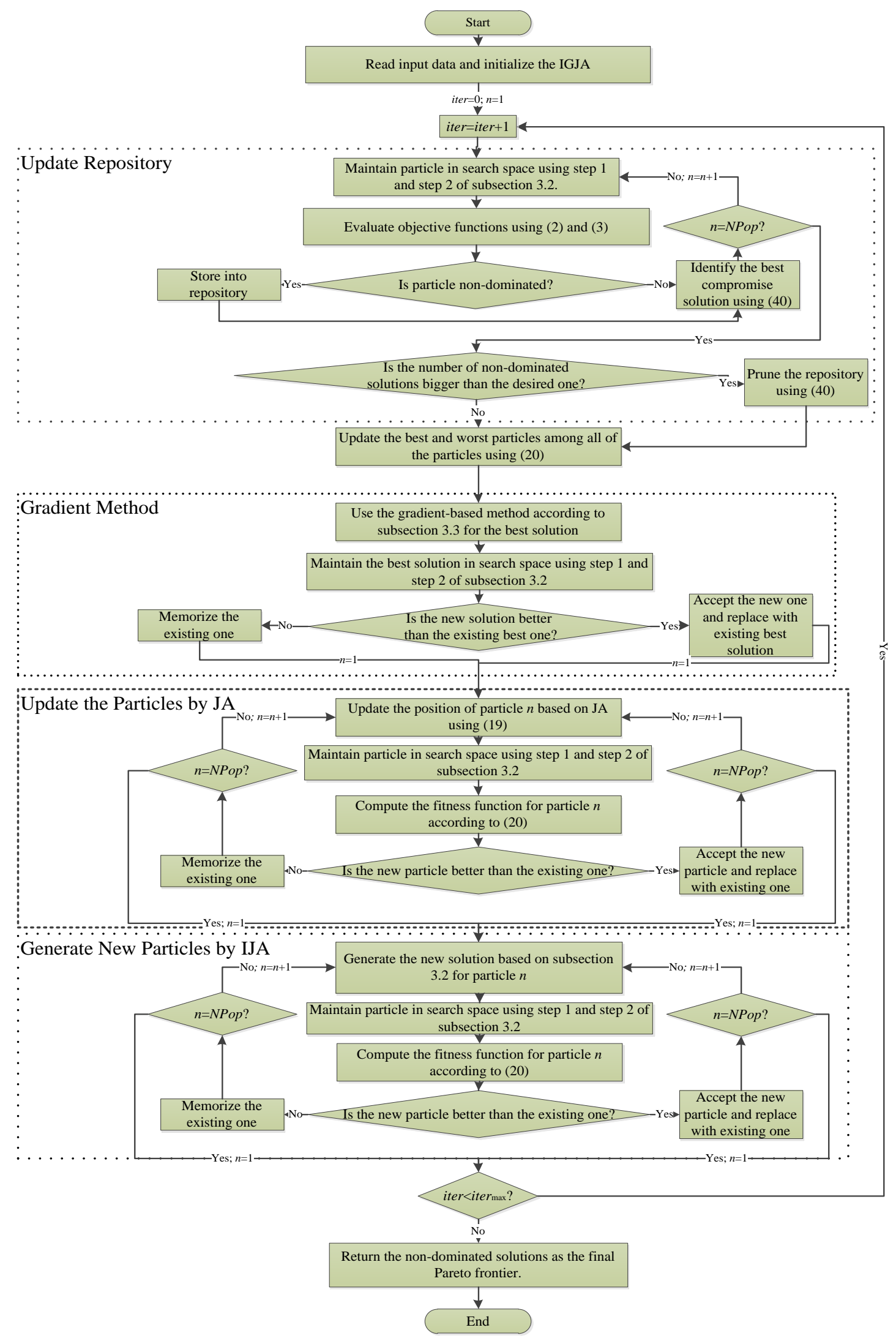

Fig. 4. Flowchart of the proposed bi-objective IGJA. 


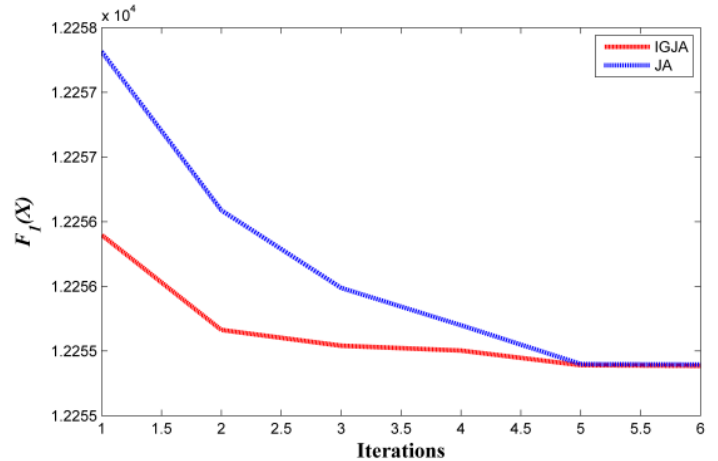

a)

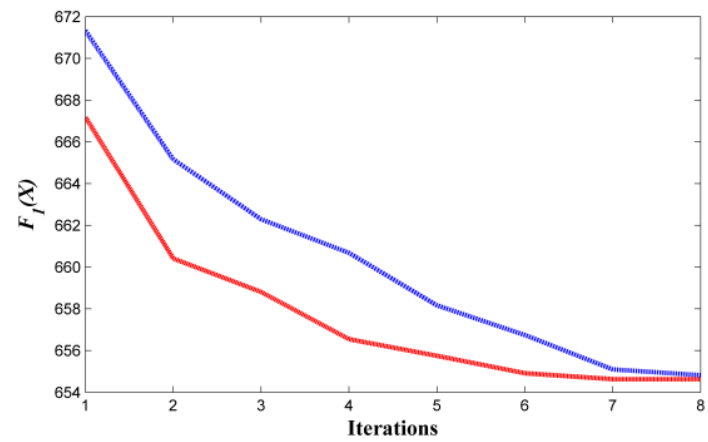

b)

Fig. 5. Convergence graph of the proposed IGJA compared to JA for (a) test system 1, (b) test system 2.

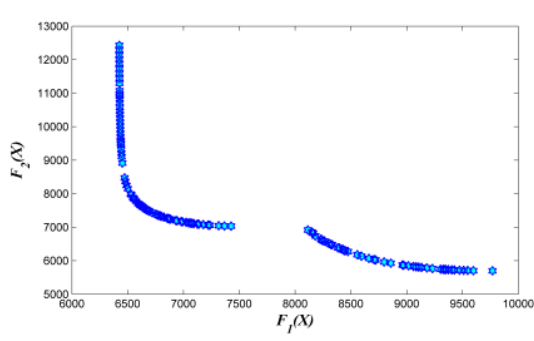

a)

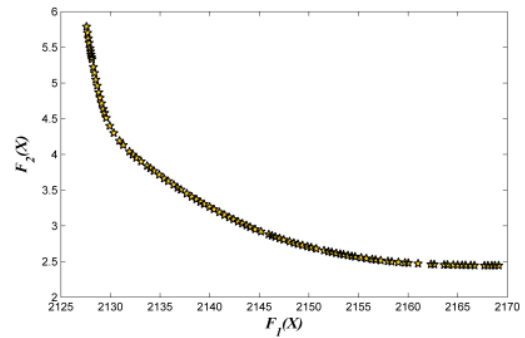

b)

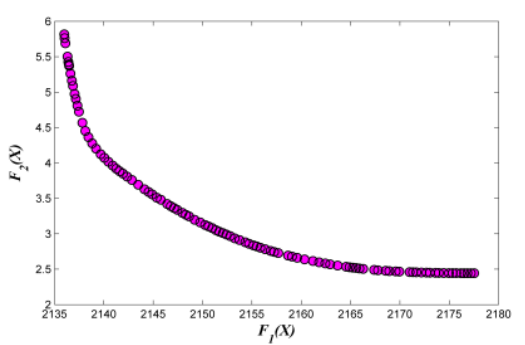

c)

Fig. 6. Pareto frontier of the proposed IGJA for (a) test system 3, Case1, (b) test system 3, Case2, and (c) test system 3, Case3.

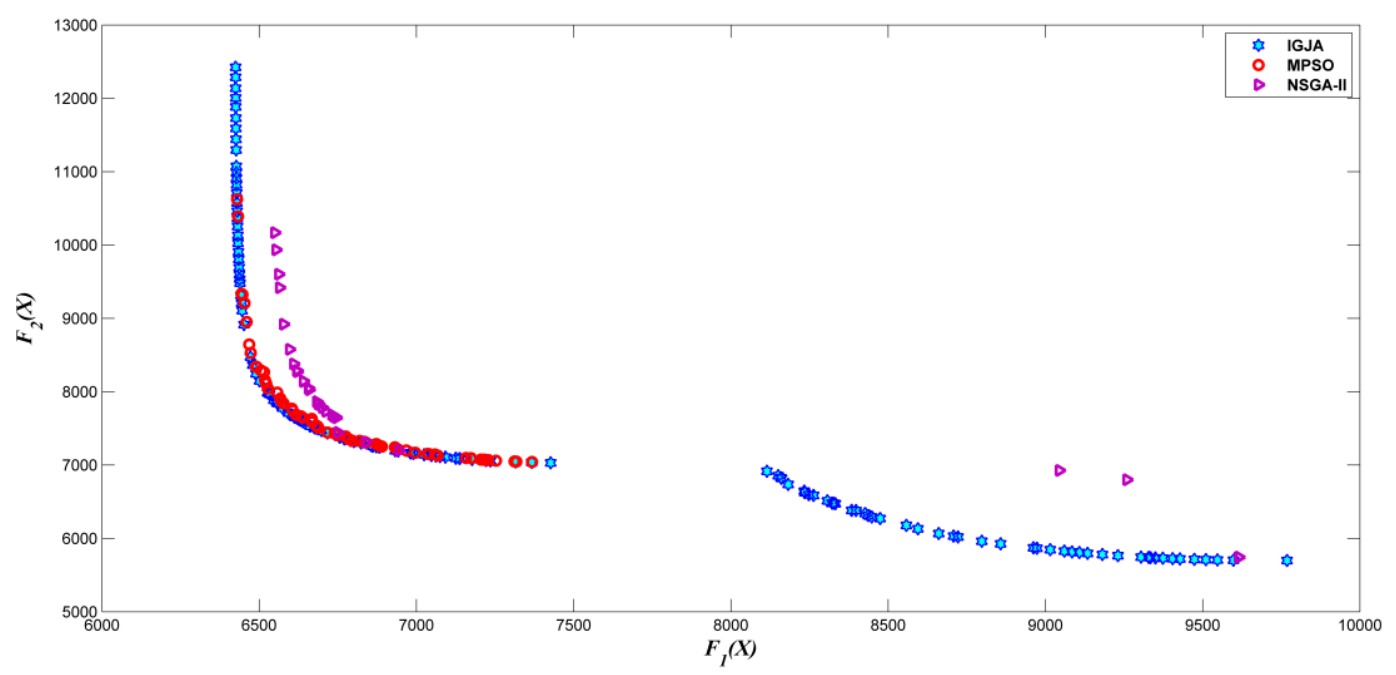

Fig. 7. Pareto frontiers obtained by proposed IGJA, MOPSO and NSGA-II for test system 3, Case1. 
IET GENERATION, TRANSMISSION \& DISTRIBUTION

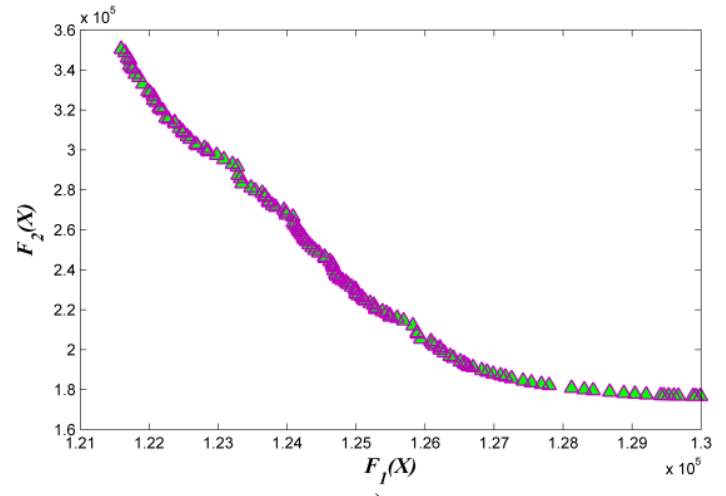

a)

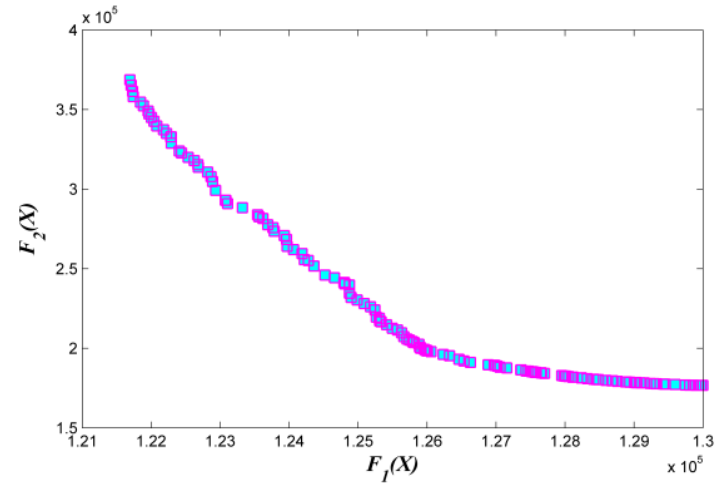

b)

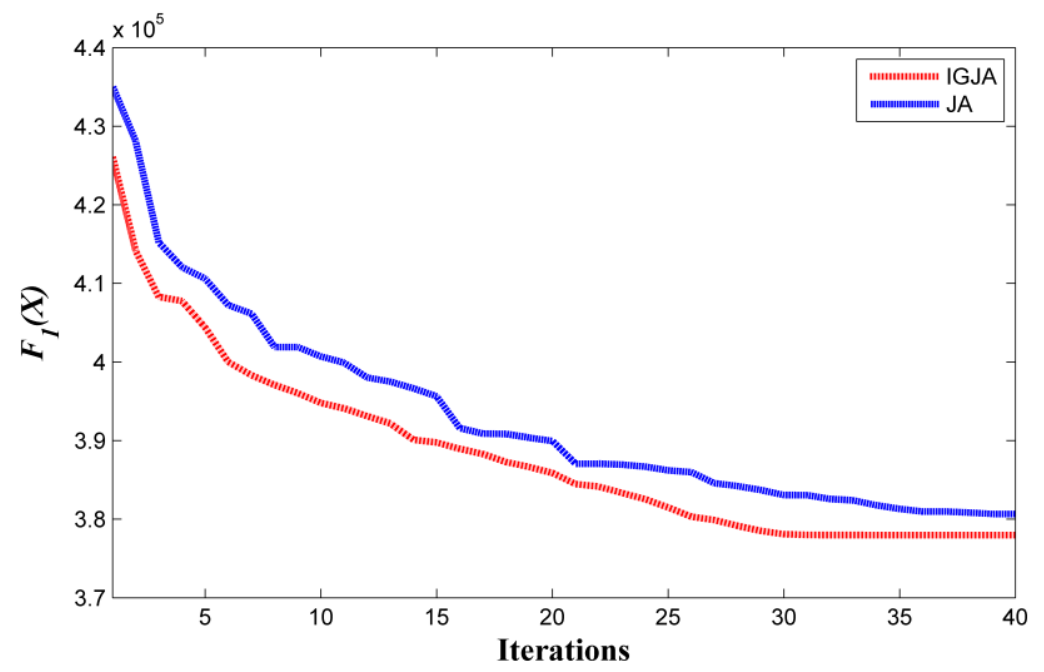

c)

Fig. 8. (a) and (b) Pareto frontiers found by the proposed IGJA for test system 4 with and without considering DPZs and (c) Convergence graph of the proposed IGJA compared to JA for test system 5. 


\section{IET GENERATION, TRANSMISSION \& DISTRIBUTION}

Table 1. Different test systems and their characteristics

\begin{tabular}{|c|c|c|c|c|c|c|c|c|c|c|c|}
\hline $\begin{array}{c}\text { Test } \\
\text { Systems }\end{array}$ & Scenarios & $N K$ & $N U K$ & $D_{k, t}$ & $\begin{array}{l}\text { Tie- } \\
\text { line } \\
\text { cost }\end{array}$ & $\begin{array}{l}\text { Valve } \\
\text {-point } \\
\text { effect }\end{array}$ & DPZ & $\begin{array}{c}\text { Multiple } \\
\text { fuel }\end{array}$ & $\begin{array}{c}\text { Transmission } \\
\text { line losses }\end{array}$ & $\begin{array}{c}\text { Up/down } \\
\text { ramp } \\
\text { rate }\end{array}$ & Reserve \\
\hline 1 & MED1 & 2 & $\begin{array}{c}3 \text { and } \\
3\end{array}$ & $\begin{array}{c}757.8 \\
\text { and } \\
505.2\end{array}$ & No & No & Yes & No & Yes & No & No \\
\hline 2 & MED1 & 3 & $\begin{array}{c}4,3 \\
\text { and } 3\end{array}$ & $\begin{array}{c}1350 \\
675 \\
\text { and } \\
675\end{array}$ & No & Yes & No & Yes & Yes & No & No \\
\hline \multirow[t]{2}{*}{3} & \multirow[t]{2}{*}{$\begin{array}{l}\text { MED1, } \\
\text { MED2, } \\
\text { MBED }\end{array}$} & \multirow[t]{2}{*}{4} & \multirow[t]{2}{*}{$\begin{array}{l}4,4, \\
4, \\
\text { and } 4\end{array}$} & $\begin{array}{l}400, \\
200, \\
350 \\
\text { and } \\
300 \\
\end{array}$ & Yes & No & No & No & No & No & No \\
\hline & & & & $\begin{array}{c}0.3, \\
0.5,0.4 \\
\text { and } 0.6\end{array}$ & No & Yes & No & No & No & No & Yes \\
\hline 4 & $\begin{array}{l}\text { MED1, } \\
\text { MED2, } \\
\text { MBED }\end{array}$ & 4 & $\begin{array}{c}10, \\
10, \\
10 \\
\text { and } \\
10\end{array}$ & $\begin{array}{c}1,575, \\
4,200, \\
3,150 \\
\text { and } \\
1,575\end{array}$ & No & Yes & Yes & No & No & No & No \\
\hline 5 & MED1 & 2 & $\begin{array}{c}70 \\
\text { and } \\
50\end{array}$ & $\begin{array}{c}18,200 \\
\text { and } \\
9,800\end{array}$ & No & No & No & No & No & Yes & No \\
\hline
\end{tabular}

Table 2: Results obtained by different techniques on test system 1

\begin{tabular}{|c|c|c|c|c|c|c|c|c|c|}
\hline \multirow[b]{2}{*}{ Units (MW) } & \multicolumn{9}{|c|}{ Algorithms } \\
\hline & RCGA [20] & EP [20] & DE [20] & ABCO [19] & TLBO [19] & CGBABC [23] & JA & IGJA & $\begin{array}{l}\text { IGJA without } \\
\text { DPZs and loss }\end{array}$ \\
\hline$g_{1,1}$ & 500.0000 & 500.0000 & 500.0000 & 500.0000 & 500.0000 & 499.9999884 & 500 & 500 & 500 \\
\hline$g_{2,1}$ & 200.0000 & 200.0000 & 200.0000 & 200.0000 & 200.0000 & 200 & 200 & 200 & 200.0000000 \\
\hline$g_{3,1}$ & 149.6328 & 149.9919 & 150.0000 & 149.9997 & 150.0000 & 149.9999954 & 150 & 150 & 150.0000000 \\
\hline$g_{1,2}$ & 205.9398 & 206.4493 & 204.3341 & 204.3358 & 204.3271 & 204.3246584 & 203.4071084 & 204.3341003 & 180.1847317 \\
\hline$g_{2,2}$ & 155.8322 & 154.8892 & 154.7048 & 154.9954 & 154.7095 & 154.7091226 & 154.7163822 & 154.7048164 & 178.6608502 \\
\hline$g_{3,2}$ & 65.2209 & 65.2717 & 67.5770 & 67.2915 & 67.5795 & 67.5823479 & 68.5015109 & 67.57701863 & 54.1544181 \\
\hline$T_{12}$ & 82.4135 & 82.7652 & 82.7731 & 82.7728 & 82.7731 & 82.77312 & 82.7727750 & 82.7731350 & 92.2000000 \\
\hline $\operatorname{Loss}_{1}$ & 9.4193 & 9.4267 & 9.4269 & 9.4269 & 9.4269 & 9.4268646325 & 9.42686500 & 9.42686500 & - \\
\hline $\operatorname{Loss}_{2}$ & 4.2064 & 4.1754 & 4.1890 & 4.1955 & 4.1892 & 4.1892497863 & 4.19777643 & 4.18907033 & - \\
\hline Error $_{1}$ & $-3.1341 \times 10^{-6}$ & $1.8960 \times 10^{-6}$ & $3.5000 \times 10^{-5}$ & $4.1181 \times 10^{-5}$ & $3.5000 \times 10^{-5}$ & $-8.3251 \times 10^{-7}$ & 0 & 0 & 0 \\
\hline Error $_{2}$ & $-3.6074 \times 10^{-5}$ & $3.4102 \times 10^{-5}$ & $-6.9426 \times 10^{-5}$ & $1.3154 \times 10^{-5}$ & $-3.6045 \times 10^{-5}$ & $-8.8629 \times 10^{-7}$ & $0.65008 \times 10^{-7}$ & 0 & 0 \\
\hline $\begin{array}{l}\text { Fuel cost } \\
\text { from } \\
\text { generation } \\
(\$)\end{array}$ & $12,255.66898$ & $12,255.42970$ & $12,255.38496$ & $12,255.38663$ & $12,255.38526$ & $12,255.38527$ & $12,255.39526$ & $12,255.38527$ & $12,130.24111$ \\
\hline $\begin{array}{c}\text { Reported } \\
\text { fuel cost }(\$)\end{array}$ & $12,256.23$ & $12,255.43$ & $12,255.42$ & $12,255.39$ & $12,255.39$ & $12,255.38527$ & $12,255.39526$ & $12,255.38527$ & $12,130.24111$ \\
\hline $\begin{array}{c}\text { CPU } \\
\text { Computation } \\
\text { Time (s) }\end{array}$ & 9.6094 & 8.8906 & 5.9219 & 10.9844 & 5.0734 & 0.8800 & 0.0985 & 0.0386 & 0.0301 \\
\hline
\end{tabular}




\section{IET GENERATION, TRANSMISSION \& DISTRIBUTION}

Table 3: Results obtained by comparing the application of different techniques on test system 2

\begin{tabular}{|c|c|c|c|c|c|c|c|c|c|c|}
\hline \multirow[b]{2}{*}{ Units (MW) } & \multicolumn{10}{|c|}{ Algorithms } \\
\hline & Fuel & RCGA [20] & EP [20] & DE [20] & $\mathrm{ABCO}[20]$ & TLBO [19] & CGBABC [23] & JA & IGJA & $\begin{array}{c}\text { IGJA without } \\
\text { loss }\end{array}$ \\
\hline$g_{1,1}$ & 2 & 239.0958 & 223.8491 & 225.4448 & 225.9431 & 224.3088 & 225.3498851 & 222.9568323 & 224.2737546 & 216.0353437 \\
\hline$g_{2,1}$ & 1 & 216.1166 & 209.5759 & 210.1667 & 211.1594 & 210.6642 & 211.9047558 & 212.39824593 & 212.1547045 & 210.9166909 \\
\hline$g_{3,1}$ & 2 & 484.1506 & 496.0680 & 491.2844 & 489.9216 & 491.6998 & 489.3519339 & 491.2078688 & 489.3573007 & 484.1809807 \\
\hline$g_{4,1}$ & 3 & 240.6228 & 237.9954 & 240.8956 & 240.6232 & 240.6247 & 240.6273431 & 240.7623494 & 241.4331992 & 238.8802026 \\
\hline$g_{1,2}$ & 1 & 259.6639 & 259.4299 & 251.0049 & 254.0397 & 249.5648 & 250.8118968 & 253.0298414 & 251.1733064 & 247.5757457 \\
\hline$g_{2,2}$ & 3 & 219.9107 & 228.9422 & 238.8603 & 235.4927 & 235.8978 & 235.7646232 & 235.7592783 & 235.7641984 & 234.4205841 \\
\hline$g_{3,2}$ & 1 & 254.5140 & 264.1133 & 264.0906 & 263.8837 & 263.7414 & 265.2630376 & 262.3542148 & 266.3883687 & 261.6482147 \\
\hline$g_{1,3}$ & 3 & 231.3565 & 238.2280 & 236.9982 & 237.0006 & 237.1327 & 237.2683096 & 238.6092132 & 236.3271037 & 234.1772066 \\
\hline$g_{2,3}$ & 1 & 341.9624 & 331.2982 & 326.5394 & 328.7373 & 332.5910 & 330.3871385 & 327.6373410 & 328.1833087 & 324.8619016 \\
\hline$g_{3,3}$ & 1 & 248.2782 & 246.6025 & 250.3339 & 248.8607 & 249.4628 & 248.8701406 & 251.0296595 & 250.5946558 & 247.3031294 \\
\hline$T_{12}$ & & -93.1700 & -100 & -99.4680 & -99.8288 & -100 & -99.9999853 & -100 & -100 & -99.9883396 \\
\hline$T_{13}$ & & -93.8739 & -100 & -100 & -99.7334 & -100 & -99.9676498 & -100 & -100 & -99.9984426 \\
\hline$T_{23}$ & & -43.7824 & -32.5231 & -30.2810 & -31.2615 & -35.4599 & -32.9091621 & -33.63174840 & -31.46384784 & -31.3437951 \\
\hline $\operatorname{Loss}_{1}$ & & 17.0297 & 17.4884 & 17.2680 & 17.2095 & 17.3000 & 17.201559419 & 17.325296399 & 17.218959016 & 0 \\
\hline $\operatorname{Loss}_{2}$ & & 9.7010 & 10.0085 & 9.7688 & 9.8488 & 9.6639 & 9.748743954 & 9.775082843 & 9.789721383 & 0 \\
\hline $\operatorname{Loss}_{3}$ & & 8.9408 & 8.6056 & 8.5905 & 8.6037 & 8.7266 & 8.648836621 & 8.644465373 & 8.641220439 & 0 \\
\hline Error $_{1}$ & & $8.24 \times 10^{-5}$ & $9.49 \times 10^{-5}$ & $2.98 \times 10^{-5}$ & $-1.15 \times 10^{-4}$ & $8.36 \times 10^{-5}$ & $-6.42 \times 10^{-6}$ & 0 & 0 & 0 \\
\hline Error $_{2}$ & & $-2.46 \times 10^{-5}$ & $1.39 \times 10^{-4}$ & $4.75 \times 10^{-5}$ & $-6.66 \times 10^{-5}$ & $-5.96 \times 10^{-5}$ & $-9.55 \times 10^{-6}$ & 0 & 0 & 0 \\
\hline Error $_{3}$ & & $9.23 \times 10^{-5}$ & $3.24 \times 10^{-5}$ & $-2.87 \times 10^{-5}$ & $4.50 \times 10^{-5}$ & $-9.80 \times 10^{-6}$ & $-5.98 \times 10^{-5}$ & 0 & 0 & 0 \\
\hline $\begin{array}{l}\text { Fuel cost } \\
\text { from } \\
\text { generation } \\
(\$)\end{array}$ & & 658.19294 & 655.97796 & 654.82991 & 654.81318 & 654.80495 & 654.70521 & 654.82073 & 654.62970 & 637.60276 \\
\hline $\begin{array}{l}\text { Reported } \\
\text { fuel cost }(\$)\end{array}$ & & 657.3325 & 655.1716 & 654.0184 & 653.9995 & 653.9977 & 654.70521 & 654.82073 & 654.62970 & 637.60276 \\
\hline $\begin{array}{c}\text { CPU } \\
\text { Computation } \\
\text { Time (s) }\end{array}$ & & 83.8438 & 78.0625 & 65.0351 & 90.4381 & 61.6719 & 21.1100 & 0.2472 & 0.1014 & 0.0891 \\
\hline
\end{tabular}


IET GENERATION, TRANSMISSION \& DISTRIBUTION

Table 4. Results obtained by comparing the application of different techniques for MED1, MED2 and MBED on test system 3-Case1

\begin{tabular}{|c|c|c|c|c|c|c|c|c|c|c|}
\hline \multirow{3}{*}{ Units (MW) } & \multicolumn{10}{|c|}{ Algorithms } \\
\hline & \multicolumn{6}{|c|}{ MED1 } & \multicolumn{2}{|c|}{ MED2 } & \multicolumn{2}{|c|}{ MBED } \\
\hline & CGBABC [23] & NFP [4] & PSO [18] & HS [14] & HHS [14] & IGJA & CGBABC [20] & IGJA & CGBABC [23] & IGJA \\
\hline$g_{1,1}$ & 150 & 150 & 150 & 150 & 150 & 150 & 66.5207067 & 66.75718759 & 126.87540954 & 67.46083526 \\
\hline $\begin{array}{l}0,1 \\
g_{2,1}\end{array}$ & 100 & 100 & 100 & 100 & 100 & 100 & 52.8691908 & 53.08948295 & 86.48162611 & 60.21294191 \\
\hline $\begin{array}{l}\delta, 1 \\
g_{3,1}\end{array}$ & 67.01425464 & 66.9700 & 67.3660 & 66.9700 & 66.8600 & 67.00854493 & 79.2482258 & 79.47373997 & 67.56408245 & 58.57822370 \\
\hline$g_{4,1}$ & 99.99999904 & 100 & 100 & 100 & 100 & 100 & 76.2889865 & 76.77491697 & 92.92597095 & 69.86866418 \\
\hline$g_{1,2}$ & 57.0015744 & 56.9700 & 56.6130 & 56.9700 & 57.0400 & 57.00813804 & 77.4657093 & 77.71182637 & 90.72876565 & 50 \\
\hline $\begin{array}{l}0,2 \\
g_{2,2}\end{array}$ & 96.25963305 & 96.2500 & 95.4740 & 96.2500 & 96.2200 & 96.26020420 & 77.8002257 & 78.13719245 & 81.46985325 & 66.21283596 \\
\hline $\begin{array}{l}8,2 \\
g_{3,2}\end{array}$ & 41.88030945 & 41.8700 & 41.6170 & 41.8700 & 41.7400 & 41.88009766 & 93.213952 & 93.45839235 & 51.20626706 & 45.25743083 \\
\hline$g_{4,2}$ & 72.50238905 & 72.5200 & 72.3560 & 72.5200 & 72.5000 & 72.50672370 & 83.8241036 & 84.19042498 & 68.52046897 & 59.56527929 \\
\hline$g_{1,3}$ & 50 & 50 & 50 & 50 & 50 & 50 & 90.1575617 & 90.32309784 & 61.75648809 & 50 \\
\hline $\begin{array}{l}8,5 \\
g_{2,3}\end{array}$ & 36.25534412 & 36.2700 & 35.9730 & 36.2700 & 36.2400 & 36.25336106 & 63.7014978 & 63.85971118 & 48.95709899 & 36.00731531 \\
\hline$g_{3,3}$ & 38.50292424 & 38.4900 & 38.2100 & 38.4900 & 38.3900 & 38.50404047 & 94.4779301 & 94.6372598 & 54.66231557 & 48.84729669 \\
\hline$g_{4,3}$ & 37.31077863 & 37.3200 & 37.1620 & 37.3200 & 37.2000 & 37.31078584 & 94.4319083 & 94.83198679 & 41.80756184 & 37.98917688 \\
\hline$g_{1,4}$ & 150 & 150 & 150 & 150 & 150 & 150 & 86.1495095 & 85.14209639 & 130.12753749 & 150 \\
\hline $\begin{array}{l}0,4 \\
g_{2,4}\end{array}$ & 100 & 100 & 100 & 100 & 100 & 100 & 59.0007298 & 58.41447890 & 86.68294222 & 100 \\
\hline $\begin{array}{l}0,4 \\
g_{3,4}\end{array}$ & 57.00777352 & 57.0500 & 57.8300 & 57.0500 & 56.9000 & 57.00803572 & 73.2077956 & 72.72781412 & 69.25955138 & 100 \\
\hline$g_{4,4}$ & 96.26501822 & 96.2700 & 97.3490 & 96.2700 & 96.2000 & 96.26006839 & 81.6419652 & 80.47039135 & 90.97406045 & 100 \\
\hline $\begin{array}{l}\delta, 4 \\
T_{12}\end{array}$ & $7.35339 \times 10^{-7}$ & 0 & 0 & 0 & 0 & 0 & -82.933808425 & -39.96253632 & -28.63191791 & -45.33910605 \\
\hline$T_{13}$ & 19.697889742 & 18.1800 & 22.5880 & 18.1800 & 16.8600 & 19.05044664 & -52.139081496 & -72.40896772 & 2.47893078 & 1.45977108 \\
\hline$T_{41}$ & 2.683635835 & 1.2100 & 5.1760 & 1.2100 & 0 & 2.04190171 & -9.999999449 & 11.53316848 & $-7.619 \times 10^{-5}$ & 100 \\
\hline$T_{23}$ & 68.23306259 & 69.7300 & 66.0640 & 69.7300 & 70.6100 & 68.88136599 & -10.629817346 & 1.428089353 & 63.28892961 & 75.69644003 \\
\hline$T_{42}$ & 0.589155905 & 2.1100 & 0.0040 & 2.1100 & 3.1100 & 1.22620240 & -60 & -92.10721048 & -0.0045074 & 100 \\
\hline$T_{34}$ & 100 & 100 & 100 & 100 & 100 & 100 & 70 & 77.32882276 & 77.04867513 & 100 \\
\hline Error $_{1}$ & $-9.6234 \times 10^{-7}$ & 0 & $-4.6 \times 10^{-2}$ & $-6 \times 10^{-1}$ & 0 & 0 & $-2.72 \times 10^{-7}$ & 0 & 0 & 0 \\
\hline Error $_{2}$ & 0 & $-1 \times 10^{-1}$ & 0 & 0 & 0 & 0 & $-4.79 \times 10^{-7}$ & 0 & 0 & 0 \\
\hline Error $_{3}$ & $-6.78 \times 10^{-7}$ & $-1 \times 10^{-1}$ & $-3 \times 10^{-3}$ & $-3 \times 10^{-2}$ & $-7 \times 10^{-1}$ & 0 & $-9.42 \times 10^{-7}$ & 0 & 0 & 0 \\
\hline Error $_{4}$ & 0 & 0 & $-1 \times 10^{-3}$ & $1 \times 10^{-1}$ & $-1 \times 10^{-2}$ & 0 & $-4.51 \times 10^{-7}$ & 0 & 0 & 0 \\
\hline $\begin{array}{l}\text { Fuel cost from } \\
\text { generation }(\$)\end{array}$ & $7,337.01396$ & $7,336.81028$ & 7,336.67492 & $7,332.26326$ & $7,329.44283$ & 7,337.01396 & $9,828.91530$ & $9,857.842548$ & $9,569.40572$ & $6,697.69791$ \\
\hline $\begin{array}{l}\text { Reported fuel cost } \\
\text { (\$) }\end{array}$ & $7,337.01396$ & $7,337.00$ & $7,336.93$ & $7,333.26$ & $7,329.85$ & 7,337.01396 & $9,828.91530$ & $9,857.842548$ & $9,569.40572$ & $6,697.69791$ \\
\hline $\begin{array}{c}\text { Emission from } \\
\text { generation (ton) }\end{array}$ & $17,184.756610$ & $17,184.63519$ & $17,189.65121$ & $17,186.07735$ & $17,180.87943$ & $17,184.72200$ & $5,697.70548$ & $5,697.14486$ & $7,727.110436$ & $7,471.11752$ \\
\hline $\begin{array}{c}\text { Reported } \\
\text { emission (ton) }\end{array}$ & $17,184.756609$ & NA & NA & NA & NA & $17,184.72200$ & $5,697.70548$ & $5,697.14486$ & $7,727.110436$ & $7,471.11752$ \\
\hline $\begin{array}{c}\text { CPU Computation } \\
\text { Time (s)-MED1 }\end{array}$ & 6.0200 & 17.8000 & 8.1560 & 11.5800 & 0.4000 & 0.0273 & - & - & - & - \\
\hline $\begin{array}{l}\text { CPU Computation } \\
\text { Time (s)-MED2 }\end{array}$ & - & - & - & - & - & - & 6.3600 & 0.0245 & - & - \\
\hline $\begin{array}{l}\text { CPU Computation } \\
\text { Time (s)-MBED }\end{array}$ & - & - & - & - & - & - & - & - & NA & 0.0281 \\
\hline
\end{tabular}

NA: Not available 
IET GENERATION, TRANSMISSION \& DISTRIBUTION

Table 5. Results obtained by comparing the application of different techniques for MED1, MED2 and MBED on test system 3-Case2

\begin{tabular}{|c|c|c|c|c|c|c|c|c|}
\hline \multirow{3}{*}{ Units (MW) } & \multicolumn{8}{|c|}{ Algorithms } \\
\hline & \multicolumn{3}{|c|}{ MED1 } & \multicolumn{3}{|c|}{ MED2 } & \multicolumn{2}{|c|}{ MBED } \\
\hline & PSO [24] & $\begin{array}{c}\text { CASE I } \\
\text { [22] }\end{array}$ & IGJA & PSO [24] & $\begin{array}{c}\text { CASE I } \\
\text { [22] }\end{array}$ & IGJA & CASE I [22] & IGJA \\
\hline$g_{1,1}$ & 0.1320 & 0.1400 & 0.1400000 & 0.1277 & 0.1004 & 0.11836915 & 0.1115606 & 0.14000000 \\
\hline$g_{2,1}$ & 0.0649 & 0.0999 & 0.1000000 & 0.0625 & 0.1000 & 0.10000000 & 0.0943248 & 0.10000000 \\
\hline$g_{3,1}$ & 0.1201 & 0.0397 & 0.0400000 & 0.1188 & 0.1006 & 0.11956406 & 0.0850709 & 0.09166400 \\
\hline$g_{4,1}$ & 0.1128 & 0.1199 & 0.1200000 & 0.0945 & 0.0988 & 0.11701390 & 0.0383869 & 0.120000000 \\
\hline$g_{1,2}$ & 0.2047 & 0.2497 & 0.2500000 & 0.1684 & 0.1449 & 0.13895918 & 0.1738436 & 0.19862765 \\
\hline$g_{2,2}$ & 0.0657 & 0.1199 & 0.1200000 & 0.0677 & 0.0793 & 0.07347976 & 0.1188736 & 0.12000000 \\
\hline$g_{3,2}$ & 0.1316 & 0.0606 & 0.1049999 & 0.1891 & 0.1235 & 0.11792123 & 0.1992356 & 0.10246391 \\
\hline$g_{4,2}$ & 0.1503 & 0.1494 & 0.1050001 & 0.1604 & 0.1266 & 0.12130768 & 0.0746936 & 0.10726303 \\
\hline$g_{1,3}$ & 0.0572 & 0.0008 & 0.0005000 & 0.0619 & 0.1242 & 0.11991663 & 0.1103756 & 0.07709005 \\
\hline$g_{2,3}$ & 0.0971 & 0.0005 & 0.0005000 & 0.0722 & 0.1218 & 0.11711100 & 0.0153371 & 0.06171960 \\
\hline$g_{3,3}$ & 0.0663 & 0.1824 & 0.1830000 & 0.0901 & 0.1174 & 0.11338182 & 0.0409648 & 0.07658940 \\
\hline$g_{4,3}$ & 0.2278 & 0.3000 & 0.3000000 & 0.1948 & 0.1203 & 0.11602852 & 0.2996616 & 0.26850719 \\
\hline$g_{1,4}$ & 0.0759 & 0.1068 & 0.1100000 & 0.0900 & 0.1100 & 0.11000000 & 0.0071000 & 0.11000000 \\
\hline$g_{2,4}$ & 0.1123 & 0.0006 & 0.0005000 & 0.1172 & 0.1143 & 0.10963045 & 0.1935572 & 0.05629710 \\
\hline$g_{3,4}$ & 0.0520 & 0.2286 & 0.2250000 & 0.0595 & 0.0909 & 0.08676283 & 0.1205024 & 0.08696574 \\
\hline$g_{4,4}$ & 0.1402 & 0.0005 & 0.0005000 & 0.1498 & 0.1262 & 0.12055379 & 0.1165175 & 0.08281234 \\
\hline$T_{12}$ & -0.0316 & -0.0599 & -0.0600000 & -0.0469 & 0.0292 & -0.00505290 & -0.0591709 & -0.00833600 \\
\hline$T_{13}$ & -0.0088 & -0.0398 & -0.0400000 & -0.0020 & -0.0400 & -0.04000000 & -0.0397930 & -0.04000000 \\
\hline$T_{14}$ & 0.1699 & 0.1995 & 0.2000000 & 0.1427 & 0.1107 & 0.20000000 & 0.1283090 & 0.20000000 \\
\hline$T_{23}$ & -0.0320 & -0.0350 & -0.0350000 & -0.020 & -0.0350 & -0.01800434 & -0.0349508 & -0.03498142 \\
\hline$T_{24}$ & -0.0516 & -0.0547 & -0.0550000 & -0.0499 & -0.0386 & 0.03538070 & -0.0424251 & -0.05500000 \\
\hline$T_{34}$ & 0.0048 & 0.0090 & 0.0090000 & -0.0089 & 0.0090 & 0.00843362 & -0.0084042 & 0.00892482 \\
\hline$R_{1}^{u p}$ & 0.0602 & 0.0902 & 0.0900000 & 0.0865 & 0.0900 & 0.03505289 & 0.1606569 & 0.03833600 \\
\hline$R_{2}^{u p}$ & 0.1977 & 0.1702 & 0.1700000 & 0.1644 & 0.2755 & 0.29833215 & 0.1833536 & 0.22164542 \\
\hline$R_{3}^{u p}$ & 0.7516 & 0.7161 & 0.7160000 & 0.7810 & 0.7160 & 0.73356203 & 0.7336609 & 0.71609377 \\
\hline$R_{4}^{u p}$ & 0.5296 & 0.5733 & 0.5740000 & 0.4935 & 0.4684 & 0.48305293 & 0.4723229 & 0.57392482 \\
\hline$R_{1}^{d n}$ & NA & NA & 0.3980000 & NA & NA & 0.45294711 & NA & 0.44966400 \\
\hline$R_{2}^{d n}$ & NA & NA & 0.5780000 & NA & NA & 0.44966785 & NA & 0.52635459 \\
\hline$R_{3}^{d n}$ & NA & NA & 0.4820000 & NA & NA & 0.46443797 & NA & 0.48190624 \\
\hline$R_{4}^{d n}$ & NA & NA & 0.3340000 & NA & NA & 0.42494707 & NA & 0.33407518 \\
\hline Error $_{1}$ & $3 \times 10^{-4}$ & $-3 \times 10^{-4}$ & 0 & $9.7 \times 10^{-3}$ & $-1 \times 10^{-4}$ & 0 & $-1.9 \times 10^{-6}$ & 0 \\
\hline Error $_{2}$ & $1.1 \times 10^{-3}$ & 0 & 0 & $8.8 \times 10^{-3}$ & $-1 \times 10^{-4}$ & 0 & $1.2 \times 10^{-6}$ & 0 \\
\hline Error $_{3}$ & $2.8 \times 10^{-3}$ & $-1 \times 10^{-4}$ & 0 & $5.9 \times 10^{-3}$ & $-3 \times 10^{-4}$ & 0 & $-5 \times 10^{-7}$ & 0 \\
\hline Error $_{4}$ & $6.7 \times 10^{-3}$ & $-3 \times 10^{-4}$ & 0 & $2 \times 10^{-4}$ & $-1 \times 10^{-4}$ & 0 & $7 \times 10^{-6}$ & 0 \\
\hline $\begin{array}{c}\text { Fuel cost from } \\
\text { generation }(\$)\end{array}$ & $2,163.5927$ & $2,127.4654$ & $2,127.5925$ & $2,178.2248$ & $2,169.5898$ & $2,169.12458$ & $2,152.21266$ & $2,137.68910$ \\
\hline $\begin{array}{c}\text { Reported fuel } \\
\text { cost }(\$)\end{array}$ & $2,166.82$ & $2,127.6741$ & $2,127.5925$ & $2,178.20$ & $2,169.8057$ & $2,169.12458$ & $2,152.21264$ & $2,137.68910$ \\
\hline $\begin{array}{c}\text { Emission from } \\
\text { generation (ton) }\end{array}$ & 3.26430 & 5.89636 & 5.78778 & 3.18285 & 2.46932 & 2.44286 & 4.65918 & 3.45047 \\
\hline $\begin{array}{c}\text { Reported } \\
\text { emission (ton) }\end{array}$ & 3.3152 & 5.8993 & 5.78778 & 3.230 & 2.47252 & 2.44286 & 4.65918 & 3.45047 \\
\hline $\begin{array}{c}\text { CPU } \\
\text { Computation } \\
\text { Time (s)- } \\
\text { MED1 }\end{array}$ & NA & NA & 0.0243 & - & - & - & - & - \\
\hline $\begin{array}{c}\text { CPU } \\
\text { Computation } \\
\text { Time (s)- } \\
\text { MED2 } \\
\end{array}$ & - & - & - & NA & NA & 0.0212 & - & - \\
\hline $\begin{array}{c}\text { CPU } \\
\text { Computation } \\
\text { Time (s)- } \\
\text { MBED }\end{array}$ & - & - & - & - & - & - & NA & 0.0296 \\
\hline
\end{tabular}

NA: Not Available 


\section{IET GENERATION, TRANSMISSION \& DISTRIBUTION}

Table 6. Results obtained by comparing the application of different techniques for MED1, MED2 and MBED on test system 3-Case3

\begin{tabular}{|c|c|c|c|c|c|c|}
\hline \multirow{3}{*}{ Units (MW) } & \multicolumn{6}{|c|}{ Algorithms } \\
\hline & \multicolumn{2}{|c|}{ MED1 } & \multicolumn{2}{|c|}{ MED2 } & \multicolumn{2}{|c|}{ MBED } \\
\hline & CASE I [22] & IGJA & CASE I [22] & IGJA & CASE I [22] & IGJA \\
\hline$\overline{g_{1,1}}$ & 0.1400 & 0.1400000 & 0.1183773 & 0.11836915 & 0.1399720 & 0.1400000 \\
\hline$g_{2,1}$ & 0.1000 & 0.1000000 & 0.1000000 & 0.10000000 & 0.0986082 & 0.1000000 \\
\hline$g_{3,1}$ & 0.0457608 & 0.0400000 & 0.1195736 & 0.11956406 & 0.0983318 & 0.0954115 \\
\hline$g_{4,1}$ & 0.1199994 & 0.1200000 & 0.1170255 & 0.11701390 & 0.1197505 & 0.1199313 \\
\hline$g_{1,2}$ & 0.2500000 & 0.2500000 & 0.1389808 & 0.13895918 & 0.1816420 & 0.1800899 \\
\hline$g_{2,2}$ & 0.1200000 & 0.1200000 & 0.0734976 & 0.07347976 & 0.0744027 & 0.1200000 \\
\hline$g_{3,2}$ & 0.2000000 & 0.0785273 & 0.1179339 & 0.11792123 & 0.1261824 & 0.1077175 \\
\hline$g_{4,2}$ & 0.0042327 & 0.1314727 & 0.1213222 & 0.12130768 & 0.1144656 & 0.1163627 \\
\hline$g_{1,3}$ & 0.0005000 & 0.0005000 & 0.1199036 & 0.11991663 & 0.0818219 & 0.0792306 \\
\hline$g_{2,3}$ & 0.0005000 & 0.0005000 & 0.1170986 & 0.11711100 & 0.0629645 & 0.0808021 \\
\hline$g_{3,3}$ & 0.1829997 & 0.1830000 & 0.1133690 & 0.11338182 & 0.1175823 & 0.0985387 \\
\hline$g_{4,3}$ & 0.2999999 & 0.3000000 & 0.1160152 & 0.11602852 & 0.1997273 & 0.2252466 \\
\hline$g_{1,4}$ & 0.1100000 & 0.1100000 & 0.1100000 & 0.11000000 & 0.0592040 & 0.1099008 \\
\hline$g_{2,4}$ & 0.0005000 & 0.0005000 & 0.1096131 & 0.10963045 & 0.0397950 & 0.0560058 \\
\hline$g_{3,4}$ & 0.1999942 & 0.2250000 & 0.0867518 & 0.08676283 & 0.1159061 & 0.0798857 \\
\hline$g_{4,4}$ & 0.0255122 & 0.0005000 & 0.1205377 & 0.12055379 & 0.1696448 & 0.0908766 \\
\hline$T_{12}$ & -0.0542329 & -0.0600000 & 0.0277957 & -0.00505290 & -0.0134335 & -0.0046571 \\
\hline$T_{13}$ & -0.0399995 & -0.0400000 & -0.0355024 & -0.04000000 & -0.0199525 & -0.0400000 \\
\hline$T_{14}$ & 0.1999930 & 0.2000000 & 0.1626831 & 0.20000000 & 0.1900481 & 0.2000000 \\
\hline$T_{23}$ & -0.0350000 & -0.0350000 & -0.0346740 & -0.01800434 & -0.0345699 & -0.0350000 \\
\hline$T_{24}$ & -0.0550000 & -0.0550000 & -0.0142043 & 0.03538070 & -0.0178287 & -0.05451300 \\
\hline$T_{34}$ & 0.0090000 & 0.0090000 & -0.0037900 & 0.00843362 & 0.0075737 & 0.0088180 \\
\hline$R_{1}^{u p}$ & 0.0842398 & 0.0900000 & 0.0350236 & 0.03505289 & 0.0333376 & 0.0346571 \\
\hline$R_{2}^{u p}$ & 0.1757673 & 0.1700000 & 0.2982655 & 0.29833215 & 0.2533073 & 0.2258299 \\
\hline$R_{3}^{u p}$ & 0.7160004 & 0.7160000 & 0.7336136 & 0.73356203 & 0.7379040 & 0.7161820 \\
\hline$R_{4}^{u p}$ & 0.5739936 & 0.5740000 & 0.4830974 & 0.48305293 & 0.5254502 & 0.5733310 \\
\hline$R_{1}^{d n}$ & NA & 0.3980000 & NA & 0.45294711 & NA & 0.4533429 \\
\hline$R_{2}^{d n}$ & NA & 0.5780000 & NA & 0.44966785 & NA & 0.5221701 \\
\hline$R_{3}^{d n}$ & NA & 0.4820000 & NA & 0.46443797 & NA & 0.4818180 \\
\hline$R_{4}^{d n}$ & NA & 0.3340000 & NA & 0.42494707 & NA & 0.3346690 \\
\hline Error $_{1}$ & $-4 \times 10^{-7}$ & 0 & 0 & 0 & $4 \times 10^{-7}$ & 0 \\
\hline Error $_{2}$ & $-2 \times 10^{-7}$ & 0 & $-1 \times 10^{-7}$ & 0 & $4 \times 10^{-7}$ & 0 \\
\hline Error $_{3}$ & $1 \times 10^{-7}$ & 0 & 0 & 0 & $-1 \times 10^{-7}$ & 0 \\
\hline Error $_{4}$ & $-6 \times 10^{-7}$ & 0 & 0 & 0 & $4 \times 10^{-7}$ & 0 \\
\hline $\begin{array}{c}\text { Fuel cost } \\
\text { from } \\
\text { generation } \\
(\$)\end{array}$ & $2,136.40511$ & $2,135.99277$ & $2,177.55342$ & $2,177.55164$ & $2,161.69911$ & $2,151.69601$ \\
\hline $\begin{array}{c}\text { Reported } \\
\text { fuel cost }(\$)\end{array}$ & $2,140.27270$ & $2,135.99277$ & $2,177.55345$ & $2,177.55164$ & 2,161.69906 & $2,151.69601$ \\
\hline $\begin{array}{l}\text { Emission } \\
\text { from } \\
\text { generation } \\
\text { (ton) }\end{array}$ & 5.93165 & 5.81572 & 2.44286 & 2.44286 & 3.08730 & 3.02967 \\
\hline $\begin{array}{c}\text { Reported } \\
\text { emission } \\
\text { (ton) }\end{array}$ & 5.93165 & 5.81572 & 2.445 & 2.44286 & 3.08730 & 3.02967 \\
\hline $\begin{array}{c}\text { CPU } \\
\text { Computation } \\
\text { Time (s)- } \\
\text { MED1 } \\
\end{array}$ & NA & 0.0250 & - & - & - & - \\
\hline $\begin{array}{c}\text { CPU } \\
\text { Computation } \\
\text { Time (s)- } \\
\text { MED2 } \\
\end{array}$ & - & - & NA & 0.0212 & - & - \\
\hline $\begin{array}{c}\text { CPU } \\
\text { Computation } \\
\text { Time (s)- } \\
\text { MBED } \\
\end{array}$ & - & - & - & - & NA & 0.0307 \\
\hline
\end{tabular}

NA: Not Available 
IET GENERATION, TRANSMISSION \& DISTRIBUTION

Table 7. Comparison of the results achieved by comparing the application of different algorithms on test system 4

\begin{tabular}{|c|c|c|c|c|}
\hline \multirow{2}{*}{$\begin{array}{l}\text { Solution } \\
\text { technique }\end{array}$} & \multicolumn{3}{|c|}{ Objective function value } & \multirow{2}{*}{$\begin{array}{c}\text { CPU } \\
\text { Computation } \\
\text { Time (s) }\end{array}$} \\
\hline & Best & Mean & Worst & \\
\hline \multicolumn{5}{|c|}{ MED1 (\$) } \\
\hline RCGA [20] & $129,911.8$ & NA & NA & 160.5300 \\
\hline $\mathrm{ABCO}[20]$ & $124,009.4$ & NA & NA & 126.9300 \\
\hline EP [6] & $123,591.9$ & NA & NA & NA \\
\hline DCPSO [16] & $121,948.8$ & NA & NA & 64.8000 \\
\hline $\mathrm{DE}[20]$ & $121,794.8$ & NA & NA & NA \\
\hline TLBO [19] & $121,760.5$ & NA & NA & NA \\
\hline CGBABC [23] & $121,595.7782$ & $121,804.3390$ & $122,393.1171$ & 52.9100 \\
\hline JA & $122,193.8780$ & $122,259.1133$ & $122,355.9162$ & 3.1401 \\
\hline IJA & $121,603.5225$ & $121,609.9522$ & $121,616.7124$ & 2.0155 \\
\hline Proposed IGJA & $121,595.7468$ & $121,595.7468$ & $121,595.7468$ & 1.2617 \\
\hline \multicolumn{5}{|c|}{ MED2 (ton) } \\
\hline CGBABC [23] & $176,682.2646$ & $176,682.2943$ & $176,684.8232$ & 45.9700 \\
\hline Proposed IGJA & $176,682.2646$ & $176,682.2646$ & $176,682.2646$ & 1.0019 \\
\hline \multicolumn{5}{|c|}{ MBED } \\
\hline & Cost $(\$)$ & Emission (ton) & & \\
\hline CGBABC [23] & $124,576.5766$ & $254,489.6408$ & & - \\
\hline Proposed IGJA & $124,278.5422$ & $254,478.0396$ & & 1.5612 \\
\hline
\end{tabular}

NA: Not Available

Table 8. Comparison of the results achieved by comparing the application of different algorithms on test system 5

\begin{tabular}{|c|c|c|c|c|}
\hline \multirow{2}{*}{$\begin{array}{l}\text { Solution } \\
\text { technique }\end{array}$} & \multicolumn{3}{|c|}{ Objective function value } & \multirow{2}{*}{$\begin{array}{c}\text { CPU } \\
\text { Computation } \\
\text { Time (s) }\end{array}$} \\
\hline & Best & Mean & Worst & \\
\hline \multicolumn{5}{|c|}{ MED1 (\$) } \\
\hline CM [44] & 399,130 & NA & NA & $5,089.0000$ \\
\hline GBABC [23] & $377,958.3312$ & $378,284.5146$ & $382,657.0553$ & 105.2100 \\
\hline JA & $380,669.5400$ & $382,181.4434$ & $383,393.0733$ & 4.7743 \\
\hline IJA & $377,968.2507$ & $378,299.5853$ & $378,669.8543$ & 3.8566 \\
\hline Proposed IGJA & $377,958.2985$ & $377,958.2985$ & $377,958.2985$ & 2.8149 \\
\hline
\end{tabular}

NA: Not Available 